\title{
Evaluation of the Influence of Antistripping Agents on Water Sensitivity of the Stone Matrix Asphalt Mixture Modified by Recycled Ground Tire Rubber and Waste Polyethylene Terephthalate
}

\author{
Alireza Ameli $\mathbb{D}^{1}$ and Rezvan Babagoli $\mathbb{D}^{2}$ \\ ${ }^{1}$ Department of Civil Engineering, Malard Branch,Azad University, Malard, Tehran, Iran \\ ${ }^{2}$ Faculty of Civil Engineering, University of Science and Technology of Mazandaran, Behshahr, Iran \\ Correspondence should be addressed to Alireza Ameli; ameli@iaumalard.ac.ir
}

Received 9 June 2021; Revised 20 August 2021; Accepted 31 August 2021; Published 1 October 2021

Academic Editor: Andrea Petrella

Copyright ( $) 2021$ Alireza Ameli et al. This is an open access article distributed under the Creative Commons Attribution License, which permits unrestricted use, distribution, and reproduction in any medium, provided the original work is properly cited.

\begin{abstract}
This research intends to evaluate the effects of the waste polyethylene terephthalate (PET), antistripping agents (ASA), and ground tire rubber (GTR) on the performance properties of the stone matrix asphalt (SMA) mix binder/water damage resistance. Liquid antistripping agents, added to 85/100 penetration grade binder to evaluate the ASA effects, were A (M500), B (EvothermM1), and C (LOF-6500). Tests conducted to study the modified bitumen's rheological properties included softening point, penetration, rotational viscosity (RV), and dynamic shear rheometer (DSR), and tests performed in order to examine the moisture sensitivity of the modified mix were the Texas boiling and resilient modulus (MR), fracture energy (FE), and indirect tensile strength (ITS) ratio tests. Results showed that the MR, ITS, and FE of asphalt mixes modified with crumb rubber (CR), ASA, and PET were improved. Adding 50\% PET, 50\% CR, and ASA (B) led to the highest tensile strength, resilient modulus, and fracture energy ratios showing a perfect water susceptibility of the mentioned mix.
\end{abstract}

\section{Introduction}

A major asphalt durability problem caused by the combined water-repeated traffic loading effect leading to structural damage under traffic load is the moisture-caused stripping that occurred when water penetrates between aggregate and bitumen film, decreases the adhesive bond, breaks and separates the asphalt film from the aggregate surface, and eliminates it $[1,2]$. To solve this problem, the mix needs sufficient bitumen compacted enough to produce impermeability.

It goes without saying that the world countries' huge industrial waste materials occupy a vast area (in their respective countries) [3-5] and pollute the soil, air, and water. Several studies have investigated the feasibility of reusing the industrial waste in order to reduce consumption of natural materials. As a major plastic-type waste material [6], PET is a semi-crystalline polyester solid thermoplastic polymer [7], the main examples of which are plastic food/liquid containers and other packaging products [8]. PET has gained popularity due to its excellent properties, suitable for flexible forming $[9,10]$. Being used to improve the mix properties, GTR is an asphalt modifier; the addition of which to the polymer-modified binder improves the bitumen behavior [6]. Among several related researches on clarifying the GTR utilization feasibility in pavements $[11,12]$, some recent ones have shown that adding CR improves the pavement performance and reduces the wheel noise on the surface [12]. Applied as a binder-mix modifier, Gilsonite consists of $57-70 \%$ asphaltene and almost $99 \%$ pure natural resinous hydrocarbons [13-15].

Since a good modifier should improve the bitumen performance against some failures, and modifying a mix with only one additive will not improve its behavior [12-14], 
this study has used more than one modifier (PET \& CR) to evaluate their combined effects [16]. The researcher intended to [17] examine the effects of PET and CR on the bitumen rheological performance and it was revealed that the improvement was noticeable. A proper mix design can improve the pavement performance against water susceptibility for which a typical technique is to use several liquid/solid ASA types (amines, diamines, and Portland cement, fly ash, flue dust, respectively) in the asphalt industry. Liquid ASAs are more popular because of their usage convenience [18]. However, as not every ASA is usable in all mixes, evaluating their effects on the mix behavior is necessary.

While some earlier researches have shown that CRmodified mixes have water vulnerability, some others have concluded that CR improves the original mix's resistance against water $[19,20]$. In view of the fact that some previous studies have indicated that adding warm additives to CRmodified mixes does not enhance resistance against water [21-23], improving water vulnerability resistance is essential. Authors of [21] examined the Zycosoil Nano additive effects on the behavior of the dry-processed CR-modified mix, which showed that water sensitivity was highly improved. In [24], the researcher studied the separate effects of two ASAs and hydrated lime on the warm additive-modified mix water sensitivity and indicated that although ASAs enhanced the ITS, they could not improve the TSR as effectively as the hydrated lime did. The researcher of [25] studied the ASA effects on the moisture vulnerability and showed that it considerably improved the performance as compared to the hydrated lime. In [26], the authors showed the specimens' improved water susceptibility/rutting resistance, and, in [27], it was indicated that, before selecting an ASA, it is necessary to check the ASA-binder compatibility. Authors of [28] evaluated the ASA effects on the specimens' water vulnerability and rutting resistance, concluding that adding ASA enhanced their behavior. Results of [29] indicated that compared to PG 64-22, PG 70-28 and 76-28 performed better with different ASA percentages. In [30], the authors studied the combined PET-CR effects on high and medium temperature behavior of two original bitumen types. They showed that viscosity increased and rutting performance improved. The 40\% PET-modified bitumen had the highest $G^{*} / \sin \delta$, parameter and adding the combined PET-CR enhanced the bitumen's high PG by two grades and improved the bitumen's medium temperature properties. The author of [31] studied the rutting behavior and moisture susceptibility of PET-contained mixes and demonstrated that properties improved in both the dry and wet processes. In [32], the authors studied the combined PET-CR effects on the rheological behavior of the CRcontaining bitumen and showed that adding PET to the CRmodified binder improved the specimen's viscosity, rutting, and fatigue. Authors of [33] examined the rheological properties of different-percentage PET-CR-modified binders and concluded that the modified outcome enhanced the bitumen's stiffness, viscosity, and high temperature performance. In [34], the authors studied the PET-/sebacic acid-/CR- modified bitumen theology and concluded that the first two helped the binder's CR anchoring, while adding
$50 \%$ PET enhanced the bitumen performance. Authors of [35] observed the effects of different content $(0.25,0.50$, and $0.75 \%$ by weight of bitumen) ASAs on the pre-/postaging bitumen performance, proving that the binder rheological behavior depended on the ASA type/percentage. While ASA reduced the binders' high storage stability after the RTFO aging, it did not change their high PG. The LAS test results revealed that ASAs improved the phase angle as well as $G^{*}$ parameters. In [36-38], the authors investigated the dryprocessed PET-modified SMA mixture performance. They pointed out that PET enhanced the specimens' Marshall Stability and volumetric parameters while it also improved the specimens' fatigue, rutting, $M R$, and resistance to moisture damage. Many researches have replaced PET with coarse and fine aggregates in pavements; in [39], the authors showed that using coarse aggregates enhanced the marshal stability and, in [40] which used fine aggregates, the mix's permanent deformation increased while its stiffness reduced.

1.1. Objectives. As mentioned before, a good modifier should improve the bitumen performance against failure. Some earlier studies [12-14] suggest that the mixture modification with merely one additive cannot achieve that; hence, more than one additive will not only modify the mixture but may also lead to the enhancement of pavement behavior due to a series of interactions [16].

Various researches have concluded that CR-modified binders' composition is nonhomogeneous, causing them to have a phase-separation problem. Therefore, efforts have been made in some studies to improve the CR-modified bitumen's storage stability through either adding multiple additives or varying its chemical composition. Sulfur with a styrene-butadiene-styrene (SBS) combination is one additive used to that end [41] and PET is another one usually used to improve the CR-modified bitumen's rheological behavior [32]. Hence, this research has used PET to enhance the bitumen's storage stability properties. Although many researches have shown that CR-modified mixes have moisture susceptibility problems, some $[19,20]$ have concluded that CR can enhance the mixtures' water damage resistance. as the fact that some studies have shown that the strength of the pavements modified by crumb rubber and warm additive is reduced against moisture [21-23], studying CR-contained mixtures' moisture susceptibility is an important task. Researches have been conducted to examine CR-/PET-modified mixes' water resistance. As ASA has been proved to enhance unmodified samples' water susceptibility performance, its applicability as well as moisture susceptibility of PET-/CR-modified mixtures need to be investigated [24]. The present study has used different PET-GTR combinations to modify bitumen and enhance its properties by adding three different ASAs to the PET-/CR-modified bitumen and evaluate its rheological behavior based on the softening point, penetration grade, rotational viscosity (RV), and DSR. Accordingly, the ITS ratio, RMR, and FER parameters were measured to study the SMA's water vulnerability. 


\section{Materials and Methods}

\subsection{Materials Used}

2.1.1. Aggregates. Tables 1 and 2 and Figure 1, respectively, show the physical and chemical properties and aggregate gradation (12.5 $\mathrm{mm}$ nominal maximum size) provided from a new quarry in Tehran, Iran, used in the present study. The aggregate used in this study is of the limestone type.

2.1.2. Bitumen. Table 3 shows the bitumen test results. AC$85 / 100$ was the only original binder type used, which was supplied by Pasargad oil refinery.

2.1.3. Fiber. To prevent the mixture from draining down, it is typically made with fibers (Table 4). According to the documented results of the National Cooperative Highway Research Program (NCHRP) Report No. 425 [42], 0.3\% cellulose fiber is the optimum bitumen content used here.

2.1.4. Crumb Rubber and PET. The GTR was a 40-mesh size made in an ambient process (CR properties are shown in Table 5), and the mix was a PET-modified mixture (Waste Plastic Bottle) made through a process in which bottles are cut into small pieces, crushed with a special crusher, and, finally, sieved to obtain the required gradation. As some studies $[1,2]$ suggest that the desired results are possible with single size PET particles in the range of $0.425-1.18 \mathrm{~mm}$, this study followed a similar procedure.

PET chips (Table 6) were first crushed and sieved to the desired dimensions and then added to the mixture in 25,50 , and $75 \%$ by weight of aggregates. Authors of [43] state that, since water acts as a hydrolysis agent, when water is under high pressure/temperature, PET is depolymerized into its monomers (Terephthalic acid). Hence, three different blends of PET and CR with constant water content were combined and each blend was separately passed through a $65 \mathrm{rpm}$ speed twin-screw extruder at $280^{\circ} \mathrm{C}$.

2.1.5. ASAs. This study has used three typical $0.5 \%$-content liquid ASAs A, B, and C (Table 7) for all the specimens.

2.2. Sample Preparation. The crumb rubber modification process of the original binder was in accordance with wet process. At first, $800 \mathrm{gr}$ of original binder was warmed up to $170^{\circ} \mathrm{C}$ in a steel bowl to reach in liquid form. After that, the additives were added gradually at $15 \%$ (three blends of PET and CR $(25 \%, 50 \%$, and $75 \%)$ by weight of original binder) to the high shear mixer and mixed at $500 \mathrm{rpm}$. After that, the temperature rose up to $190^{\circ} \mathrm{C}$, and also the speed of high shear mixer increased up to $4000 \mathrm{rpm}$ for $2 \mathrm{~h}$. At last, in order to eliminate air bubbles, which were produced in the high shear mixer in producing procedure, the specimens were located in a vacuum oven for $30 \mathrm{~min}$ at $120^{\circ} \mathrm{C}$. It is suggested by previous papers to blend ASAs with binder instead of adding them to mixture [43]. So, three ASAs with the constant percentage of $0.5 \%$ by weight of binder were
TABLE 1: Physical properties of the aggregates.

\begin{tabular}{lcc}
\hline Aggregate tests & Result & Test methods \\
\hline Bulk specific gravity & 2.493 & ASTM C127 \\
Absorption coarse aggregate (\%) & 2.2 & ASTM C127 \\
Absorption fine aggregate (\%) & 4.2 & ASTM C128 \\
Los Angeles abrasion loss (\%) & 22.3 & AASHTO T96 \\
Two fractured faces (\%) & 94 & ASTM D5821 \\
\hline
\end{tabular}

utilized into CR-/PET-modified binder and mixed by a high shear mixer at $1000 \mathrm{rpm}$ for $45 \mathrm{~min}$. Several samples with different ASA were fabricated, and sample identification of modified binders is shown in Table 8 .

The NCHRP Report No. 425 was used to design and fabricate the SMA mixtures [30]. The SMA design is based on the volumetric properties of the mixture. Some key criteria are air voids, voids in mineral aggregate, and the VCA or voids in coarse aggregate ratio that is an indicator of the stone-on-stone contact. The later is the most important factor affecting the performance of SMA mixtures. In this study different SMA mixtures have been designed with $12.5 \mathrm{~mm}$ NMAS gradations. For this gradation, three trial gradations were prepared. The three trial blends were along the coarse and fine limits of the gradation band along with one gradation falling in the middle. The next step was to check the aggregate skeleton by determination of voids in coarse aggregate in dry-rodded condition $\left(\mathrm{VCA}_{\mathrm{DRC}}\right)$. The test was carried out on the coarse aggregate fraction of any gradation. For instance, the coarse fraction is that portion of the total aggregate blend retained on No. 4 sieve for $12.5 \mathrm{~mm}$ and $19 \mathrm{~mm}$ NMASSMA mixtures. For $9.5 \mathrm{~mm}$ NMASSMA mixture, the stone is that portion of aggregate blend retained on No. 8 sieve. Two replicates of any gradation were tested, and the average results were used. The test was carried out according to AASHTOT19. For each trial gradation, an initial trial asphalt binder content of 6.2 percent was selected, and three specimens were compacted by 50 blows of Marshall hammer in accordance with ASTM D 1559. Seventy-five compaction blows were not used because this would not result in a significant increase in density over that provided by 50 blows. SMA mixtures have been more easily compacted to the desired density on the roadway than with the effort required for conventional hot-mix asphalt mixtures. The optimum gradations were then selected based on analysis results for Va, VMA, and VCA ratio. The optimum gradation is that which satisfies the minimum requirements in a way that provides VMA greater than $17 \%$, VCA ratio less than or equal to 1 , and Va between 3 and 4 percent. Based on the results, it was concluded that the optimum gradation falls in the middle band for NMAS $12.5 \mathrm{~mm}$.

The next step in the design of the SMA mixtures was to determine the optimum bitumen content. For this purpose, nine compacted replicates and three uncompacted ones were prepared for each gradation. The volumetric analyses were then conducted, and VCAmix, VMA, and Va were determined. The following equations were mainly used for the purpose of volumetric analysis of the mixtures: 
TAble 2: Aggregate's chemical properties.

\begin{tabular}{lcccccccc}
\hline \multirow{2}{*}{ Type } & \multicolumn{3}{c}{ Oxide content (\%) } \\
& $\mathrm{SiO}_{2}$ & $\mathrm{Al}_{2} \mathrm{O}_{3}$ & $\mathrm{Fe}_{2} \mathrm{O}_{3}$ & $\mathrm{Na}_{2} \mathrm{O}$ & $\mathrm{K}_{2} \mathrm{O}$ & $\mathrm{MgO}$ & $\mathrm{CaO}$ & $\mathrm{MnO}$ \\
\hline Limestone aggregate & 17.52 & 2.11 & 0.94 & 0.08 & 0.66 & 0.75 & 43.01 & 0.046 \\
\hline
\end{tabular}

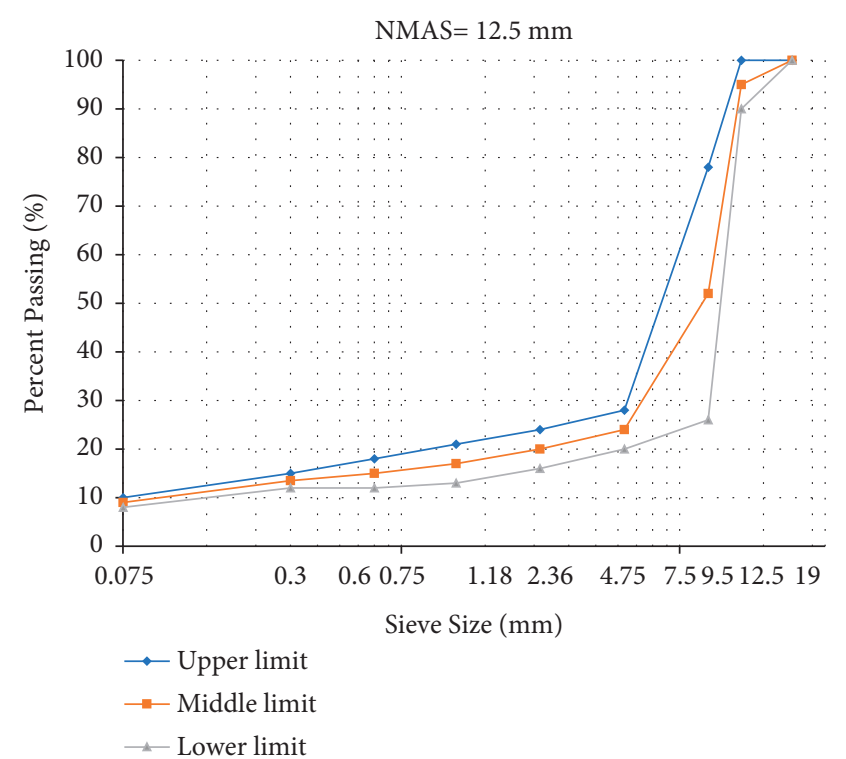

FIgURE 1: Aggregate distribution with NMAS $=12.5 \mathrm{~mm}$.

TABLE 3: Binder properties.

\begin{tabular}{lccc}
\hline Test & Method & Unit & Result \\
\hline Penetration at $25^{\circ} \mathrm{C}, 100 \mathrm{~g}$ & ASTM D5 & $0.1 \mathrm{~mm}$ & 95 \\
Softening point & ASTM D36 & ${ }^{\circ} \mathrm{C}$ & 45 \\
Ductility at $25^{\circ} \mathrm{C}$ & ASTM D113 & $\mathrm{cm}$ & +100 \\
Flash point & ASTM D92 & ${ }^{\circ} \mathrm{C}$ & 270 \\
Specific gravity at $25^{\circ} \mathrm{C}$ & ASTM D70 & $\mathrm{g} / \mathrm{cm}^{3}$ & 1.0142 \\
\hline
\end{tabular}

TABLE 4: Fibers' properties.

\begin{tabular}{lc}
\hline Properties & Value \\
\hline Cellulose fiber & \\
Cellulose content $(\%)$ & 80 \\
Ave. fiber length $(\mathrm{mm})$ & 1.1 \\
Ave. fiber thickness $(\mathrm{mm})$ & 0.045 \\
$\mathrm{pH}(5 \mathrm{~g} / 100 \mathrm{ml})$ & 7.5 \\
Bulk density $\left(\mathrm{g} / \mathrm{cm}^{3}\right)$ & 0.5 \\
\hline
\end{tabular}

TABle 5: Properties of crumb rubber.

\begin{tabular}{lc}
\hline Specifications & Result \\
\hline Ingredients & Processed rubber carbon, sulfur \\
Physical state & Solid \\
Color & Dark \\
Odor & Mild rubber \\
Specific gravity & $1.10-1.15$ \\
Bulk density & $0.34-0.35 \mathrm{~g} / \mathrm{cm}^{3}$ \\
pH values & $\mathrm{N} / \mathrm{A}$ \\
Boiling point & - \\
Solubility & Insoluble \\
\hline
\end{tabular}

Table 6: Properties of PET.

\begin{tabular}{lcc}
\hline Property & Used standard & Value \\
\hline Density $\left(\mathrm{g} / \mathrm{cm}^{3}\right)$ & ASTM D 792 & 1.35 \\
Water absorption $(\%)$ & ASTM D 570 & 0.1 \\
Tensile strength $(\mathrm{psi})$ & ASTM D 638 & 11500 \\
Melting temperature $\left({ }^{\circ} \mathrm{C}\right)$ & ASTM D 7138 & 250 \\
\hline
\end{tabular}

$$
\begin{aligned}
\mathrm{VCA}_{\mathrm{DRC}} & =\frac{G_{\mathrm{CA}} \gamma_{w}}{G_{\mathrm{CA}}} \gamma_{w} \times 100, \\
\mathrm{VCA}_{\mathrm{MIX}} & =100-\left(\frac{G_{m b}}{G_{\mathrm{CA}}} \times P_{b p}\right), \\
P_{b p} & =P_{s} P A_{b p},
\end{aligned}
$$

where $\mathrm{VCA}_{\mathrm{DRC}}$ is the voids in coarse aggregate in dryrodded condition, $\mathrm{VCA}_{\text {mix }}$ is the VCA of the compacted mixture, $P_{b p}$ is the percent of aggregate by weight of the mixture remaining on the breaking point sieve, $P_{s}$ is the percent of aggregate in the mixture, and $P A_{b p}$ is the percent of aggregate by the total weight of the aggregate remaining on the breaking point sieve.

Regarding the climatic regions in Iran that are suitable for the construction of SMA courses, the air voids were designated to be 4 percent to avoid bleeding distress. From the analysis, the bitumen content associated with this Va was determined to be $7.5 \%$. In this study, for each mixture type and test, three samples were fabricated, and the results are the average of three samples.

Subsequently, 9 compacted and 3 loose samples were made for each gradation and the optimum bitumen content was found to be $7.5 \%$ based on the volumetric properties.

\section{Experimental Program}

3.1. Binder Tests. To study the virgin/modified binders' physical performance, use was made of the conventional penetration, softening point, and ductility tests. As for assessing the rheological properties, the DSR, BBR, and RV tests were applied, and to evaluate their high/medium temperature behavior, the DSR test was done at $64^{\circ} \mathrm{C}$ and $25^{\circ} \mathrm{C}$ temperatures, respectively [44]. In the present study, Anton PaarDSR with its parallel-plate geometry loading device and a control and data acquisition system were utilized for conducting the MSCR test. Specimens were tested in replicates, using a $25 \mathrm{~mm}$ disc and with $1 \mathrm{~mm}$ gap setting at a temperature of $64^{\circ} \mathrm{C}$ and at a stress of 100 and $3200 \mathrm{~Pa}$ and aged through RTFO process. The tests were performed at the selected temperatures using a constant stress creep of 1-second duration and a relaxation period of 9 seconds, for ten cycles at each stress level. According to AASHTOT315, the $G^{*} / \sin \delta$ parameter is evaluated using the 
Table 7: Properties of used ASAs.

\begin{tabular}{lccc}
\hline Properties & M5000 & M1 & LOF-6500 \\
\hline Ingredients & Alkylamines; alkanol amines; alkylene amines & Fatty amines derivatives & Amidoamines \\
Physical state & Liquid & Liquid & Liquid \\
Color & Brown (dark) & Amber (dark) & Brown \\
Odor & Fishy & Amine-like & - \\
Specific gravity & 1.09 & 0.97 & - \\
Vapor density & 4.6 & - & - \\
pH values & 11.9 & $10-12$ & - \\
Boiling point & $255 \mathrm{C}$ & $>200 \mathrm{C}$ & - \\
Flash point & Closed up: $146 \mathrm{C}$ & Closed up: $>204.4 \mathrm{C}$ & $>200 \mathrm{C}$ \\
Solubility & - & $0.02 \mathrm{~g} / \mathrm{l}$ & - \\
\hline
\end{tabular}

TABle 8: Different specimens fabricated in the current research.

\begin{tabular}{|c|c|c|c|c|c|}
\hline No. & Virgin binder & PET (\%) & CR (\%) & ASA & Sample ID \\
\hline 1 & & 0 & 0 & - & Control \\
\hline 2 & & 25 & 75 & - & PC1 \\
\hline 3 & & 50 & 50 & - & PC2 \\
\hline 4 & & 75 & 25 & - & PC3 \\
\hline 5 & & 25 & 75 & A & PC1A \\
\hline 6 & & 50 & 50 & A & $\mathrm{PC} 2 \mathrm{~A}$ \\
\hline 7 & $85-100$ & 75 & 25 & A & PC3A \\
\hline 8 & & 25 & 75 & B & PC1B \\
\hline 9 & & 50 & 50 & B & PC2B \\
\hline 10 & & 75 & 25 & B & PC3B \\
\hline 11 & & 25 & 75 & $\mathrm{C}$ & $\mathrm{PC} 1 \mathrm{C}$ \\
\hline 12 & & 50 & 50 & $\mathrm{C}$ & $\mathrm{PC} 2 \mathrm{C}$ \\
\hline 13 & & 75 & 25 & $\mathrm{C}$ & PC3C \\
\hline
\end{tabular}

Dynamic Shear Rheometer (DSR) at the frequency of 10 rads $(1.6 \mathrm{~Hz})$. An $8 \mathrm{~mm}$-diameter plate with a $2 \mathrm{~mm}$ testing gap or a $25-\mathrm{mm}$-diameter plate with a $1 \mathrm{~mm}$ testing gap is utilized in this test. The selection of the testing geometry is based on the operational conditions, so that generally the $25-\mathrm{mm}$ plate geometry is used at high temperatures $\left(46-82^{\circ} \mathrm{C}\right)$ and the $8 \mathrm{~mm}$ plate geometry is used at low and intermediate temperatures $\left(13-31^{\circ} \mathrm{C}\right)$. According to AASHTOT315, to control the fatigue cracking of asphalt binder, $G^{*}$. Sin $\delta$ should be less than $5000 \mathrm{kPa}$ for aged binder obtained from Rolling Thin Film Oven (RTFO) and Pressure Age Vessel (PAV) tests. The dynamic shear rheometer test was performed at the frequency of $10 \mathrm{rad} / \mathrm{s}(1.59 \mathrm{~Hz})$ at a temperature of $25^{\circ} \mathrm{C}$ to evaluate fatigue behavior of the binder. Rotational viscosity test was conducted in order to assure bitumen pumping and bitumen mixing with hot aggregates. According to ASTM D4402 recommendations, bitumen viscosity should be less than $3.0 \mathrm{~Pa} . \mathrm{s}$ at $135^{\circ} \mathrm{C}$.

3.2. Moisture Sensitivity Testing Program. To study the moisture sensitivity, the Fracture Energy Ratio (FER), Resilient Modulus Ratio (RMR), Texas boiling, and TSR tests were applied.

3.2.1. ITS Test. For a pavement, the tensile strength is an imperative property calculable by the ITS test generally done to find the moisture vulnerability. It was carried out at $25^{\circ} \mathrm{C}$ (ASTM D6931-12) to find the 'ITS' as follows:

$$
\mathrm{ITS}=\frac{2 P \max }{\pi D t} .
$$

AASHTO T283 recommends the water sensitivity test to investigate the moisture resistance of specimens with $7 \pm 1 \%$ air voids. Six specimens were prepared for each mixture type and divided into two groups: 3 were conditioned based on the AASHTO T283 standard, and 3 were tested under dry conditions. Then, the wet-to-dry tensile strength ratio (TSR) was found as follows:

$$
\mathrm{TSR}=\frac{\mathrm{ITS}_{\mathrm{wet}}}{\mathrm{ITS}_{\mathrm{dry}}},
$$

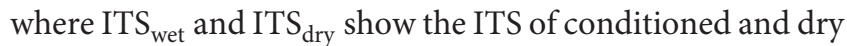
samples, respectively.

Based on standard recommendations, mixtures should have the minimum TSR value of 0.8 to be resistant against moisture damage [45].

3.2.2. $M_{R}$ Test. Using the ASTM D 4123 Standard to do the MR test, samples were grouped in two: one was kept dry at $25^{\circ} \mathrm{C}$ (referred to as unconditioned) and the other was conditioned in water based on the AASHTO T283. Finally, the RMR parameter $\left(M_{r \text { wet }} / M_{r \text { dry }}\right)$ was measured, for which the minimum adequate value was $80 \%$ [36]:

$$
M_{R}=\frac{P(v+0.2734)}{\delta t}
$$


where $P$ is the maximum applied load $(N), v$ is the Poisson's ratio, $t$ is the sample length $(\mathrm{mm})$, and $\delta$ is the horizontal recoverable deformation $(\mathrm{mm})$.

3.2.3. Fracture Energy. The idea in some earlier lab/field studies that "the fracture work/energy is a good asphalt mix fatigue performance indicator" was later proved by several others to show that the fracture energy from the IDT test correlated with the asphalt mix fatigue life. The NCHRP 949A used the fracture work as the mentioned indicator and field survey results verified this hypothesis [46, 47]. As such, the fracture energy for dry and conditioned specimens was used to study the water sensitivity. The FE (Figure 2) was found as follows [48]:

$$
\text { fracture energy }=\frac{\int_{0}^{\delta \max } P(\delta) d(\delta)}{H D},
$$

where fracture energy means total energy at failure $\left(\mathrm{J} / \mathrm{m}^{2}\right), \mathrm{P}$ is load $(\mathrm{N}), d$ is deformation $(\mathrm{mm})$, and $\mathrm{H}$ and $\mathrm{D}$ (both $\mathrm{mm}$ ) are the sample height and diameter, respectively. FER (mixture resistance against moisture) is found as follows:

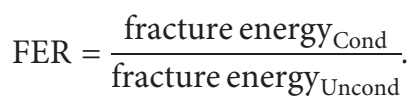

3.2.4. Texas Boiling Test. An ASTM D3625-based approach to examine the loose mix water vulnerability is the Texas boiling test, by which the reduction percentage in the binder-covered surface area of the aggregate is evaluated when prepared in boiling water. The mixture moisture sensitivity was found visually by the bitumen color and the aggregate binder-coated surface area. The loose specimen was now placed in a pan of boiling water for $10 \mathrm{~min}$ and blended for $10 \mathrm{sec}$ every $3 \mathrm{~min}$. Then, it was removed from the pan and put on a white surface to find the percent bitumen-covered area [49-51]. The percent reduction in the binder-covered surface area was found as follows:

$$
X \%=\left(\frac{(A \%-\mathrm{B} \%)}{(\mathrm{A} \%)}\right) \times 100,
$$

where $X$ is the decrease in the binder-covered surface area, $A$ is the unconditioned binder-covered surface area, and $B$ is the conditioned binder-covered surface area.

Since the Texas boiling test depends on the researcher's peripheral vision to distinguish the extent of the bindercovered surface area, the mixture water sensitivity is measured empirically. Nonetheless here, MATLAB was used to analyze each mixture's pre-/posttest images to determine this reduction accurately.

\section{Results}

4.1. Binder Test Results. The bitumen test results are shown in Figures 3-5 where using PET and CR with the original bitumen improved its rheological behavior; the penetration grade was reduced and the softening point was increased due to, probably, the binder stiffening. According to the results,

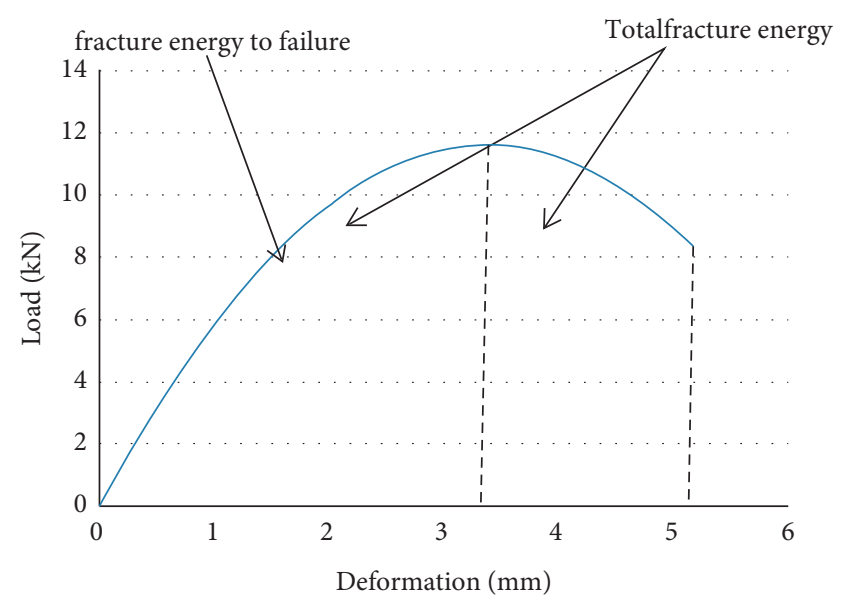

Figure 2: Schematic for fracture energy to failure.

the bitumen stiffness increased as the percent PET/rubber increased [30-33]. Earlier studies had indicated that the PET-/CR-modified bitumen has higher resistance to rutting and fatigue cracking compared with the virgin type [30].

An increase in ASA (A) increased the softening point and reduced the penetration. The latter also occurred when ASAs were used for the PET-/CR-modified bitumen. The greatest reduction was for ASA (B), while the lowest was for ASA (C). Obviously, modifiers stiffened the bitumen and hence improved the mixture properties against rutting. Regarding the softening point, ASA (B) led to a greater increase compared to other ASAs.

In Figure 5, the increase in the virgin bitumen viscosity due to PET/CR addition causes the mixture placement/ compaction operations to become harder. According to the results, increasing the percent $\mathrm{PET} /$ rubber leads to a stiffer and more viscous binder and using ASAs increases the viscosity of the PET-/CR-modified bitumen. However, different ASAs do not affect the viscosity uniformly. In increasing the bitumen viscosity, ASAs (A), (B), and (C) stand as $1^{\text {st }}, 2^{\text {nd }}$ and $3^{\text {rd }}$, respectively. Previous studies [30-35] have not only confirmed this issue, but have also shown that adding PET/CR composites to bitumen improves processing properties such as the viscosity and thermal stability.

The higher $G^{*} / \sin \delta$ bitumen resists rutting better. To this end, the virgin and RTFO aged bitumen should have a resistance of at least 1 and $2.2 \mathrm{kPa}$. Figure 6 shows the $G^{*} /$ $\sin \delta$ parameter for all types of pre-/postaging RTFO binders. As displayed, it was improved for PET-/CR-modified binder, meaning that the latter has stiffened and has, thus, increased the respective mixture's rutting resistance. Previous studies [30-35] have not only confirmed this issue, but have also shown that adding PET/CR composites to bitumen improves its performance.

As the results suggest, an increase in the $\mathrm{PET} / \mathrm{CR}$ ratio increases the binder stiffness, causing the rutting resistance to increase accordingly. As PET is a thermoplastic material and stiffens the bitumen more than the rubber part, more PET can increase the rutting resistance. Tests have shown that binder samples with higher PET contents in their 


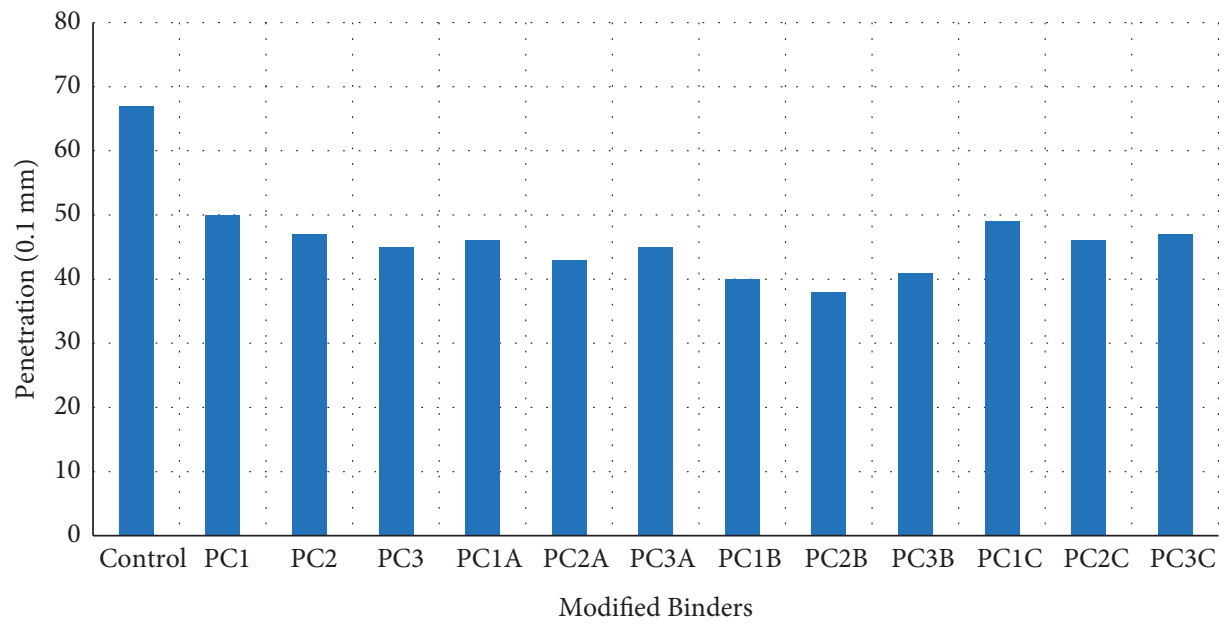

Figure 3: Penetration results of different asphalt binders.

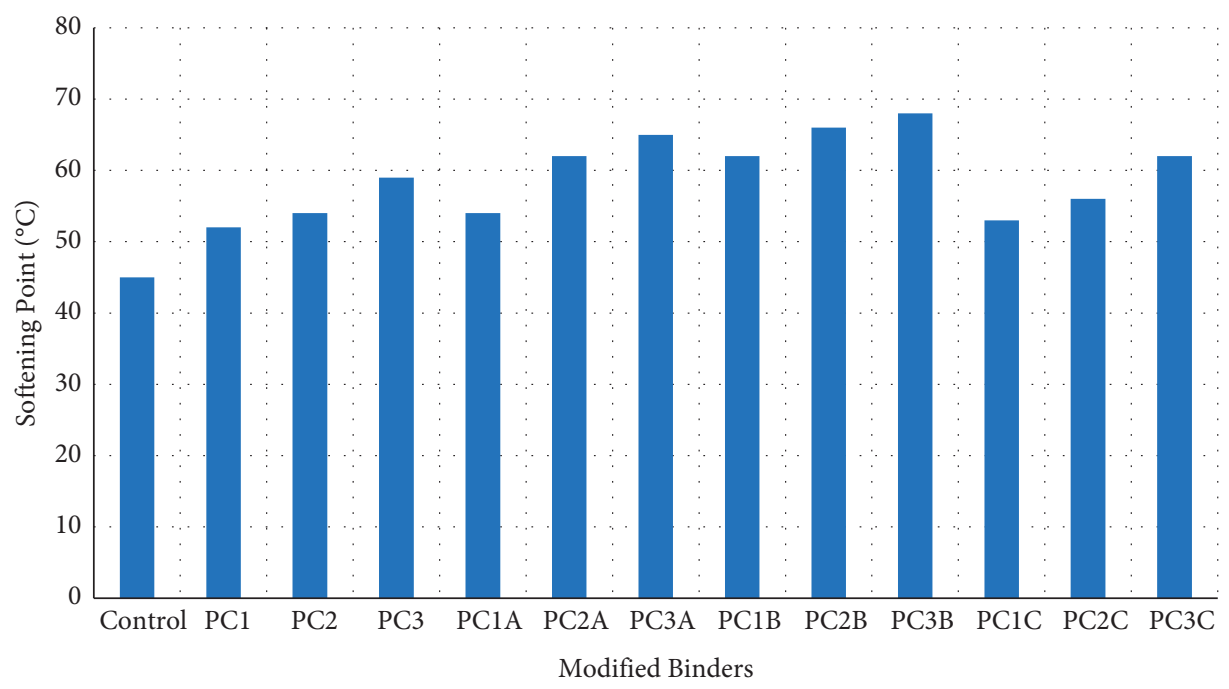

Figure 4: Softening point of different asphalt binders.

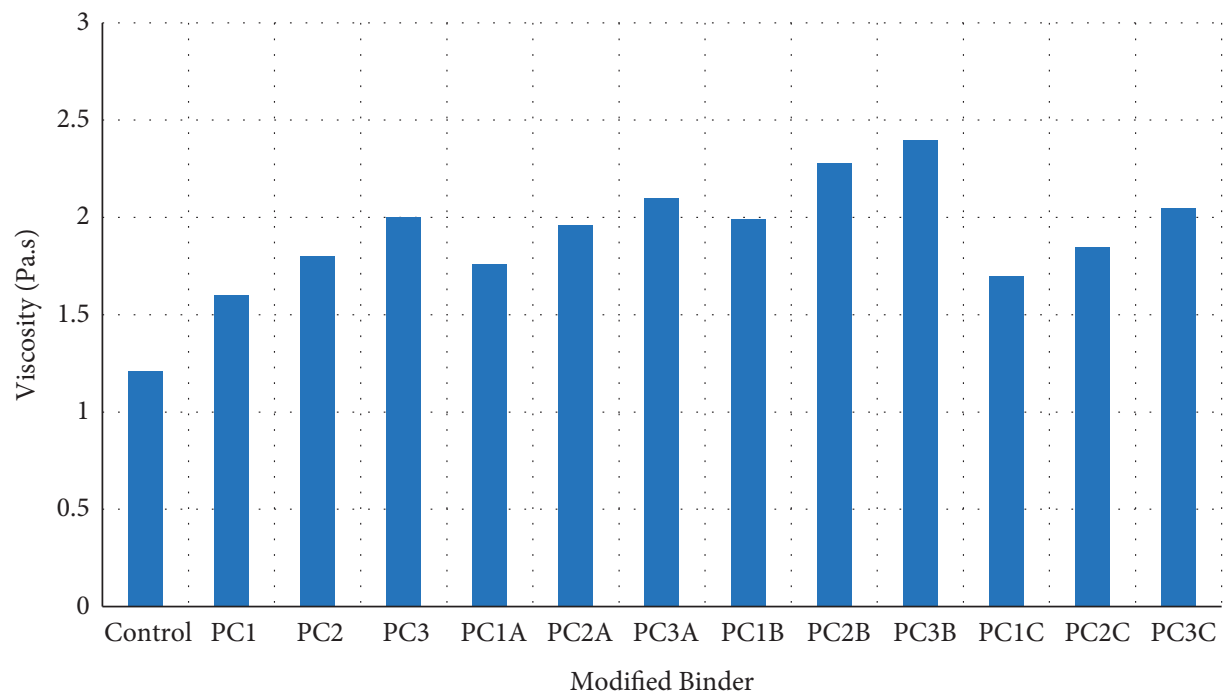

Figure 5: Rotational viscosity of modified binders. 


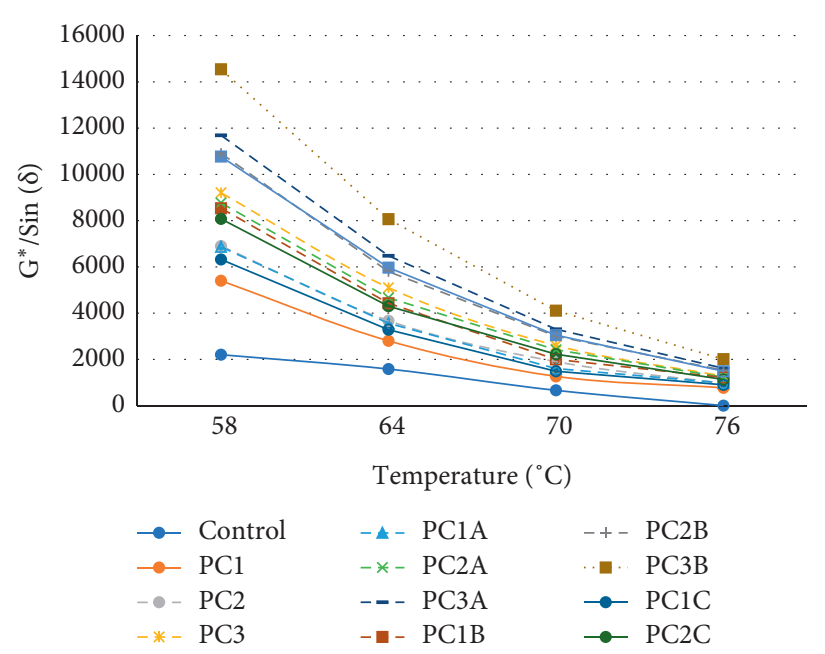

(a)

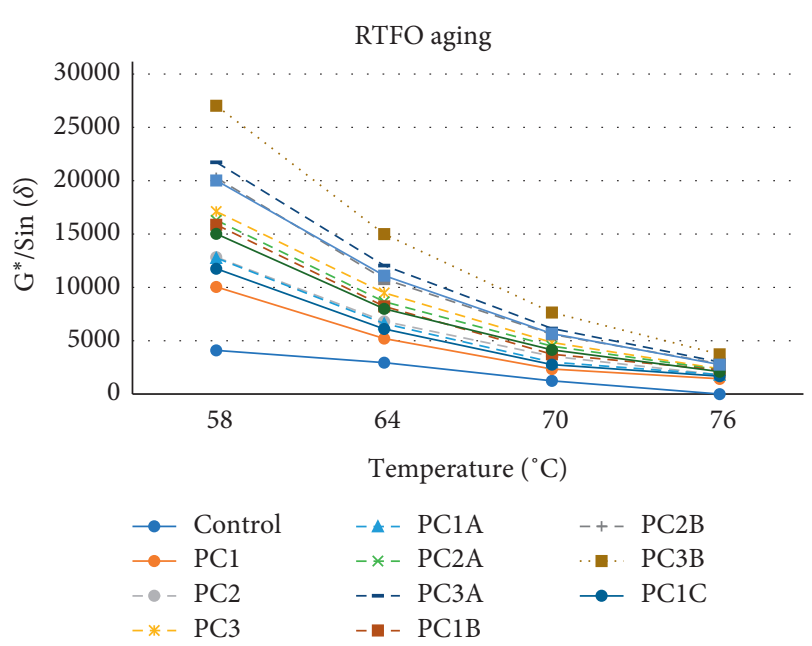

(b)

FIgURE 6: Rutting parameter of base and modified asphalt binders: (a) before aging; (b) after aging.

structure have higher storage moduli, meaning that composites rich in PET stiffen the binder-polymer interface. But those rich in CR behave like dispersed elements, instead of bitumen, improving the binder's storage modulus due to their stiffer structure than binder [46].

Regardless of their types, ASAs increase the rutting parameter. Mixes modified by ASA (B) are more rut resistance probably because organogels are formed when ASAs are added to the PET-/CR-contained bitumen. The addition of PET/CR to the original binder leads to the enhancement of the flexibility of binder. As the flexibility of binder increases, its ability to recover the applied strain improves. Moreover, the flexibility of binder increases by adding ASAs. As the results show, mixtures containing ASAs have higher strength against rutting.

In Figure 6(b), $G^{*} / \sin \delta$ has increased after the RTFO aging process probably due to the vaporization of the bitumen volatile elements and conversion of aromatics and resins to asphaltene $[52,53]$. In general, all ASAs improved the permanent deformation properties of the PET-/CRcontained bitumen and the highest rutting parameter was recorded for ASA (B) with $0.75 \%$ PET and 0.25 CR.

\subsection{Results of Mixtures}

4.2.1. MR Test Results. The MR test results for SMA specimens modified by different additives are shown in Figure 7, where the PET/CR addition has increased the MR of the mixtures more than the virgin one. As mentioned before, as PET is a thermoplastic material that stiffens the bitumen more than the rubber part, an increase of up to 50\% PET and $50 \%$ CR in the PET/CR ratio increased the mixtures' resilient modulus, but higher PET percentages reduced it (also mentioned in [30-35]). Previous studies confirmed that the addition of PET/CR improved this modulus [31-35] and stated that an increase in CR in the PET/CR ratio declined the additive distribution in the bitumen matrix due to, maybe, the CR partial cross-linking and low thermoplastic
PET swelling [54]. This might be due to the formation of a continuous elastic network and rubber powder as an elastic component compensates the undesirable (stiffening) effects of PET as the plastic constituent resulting in improved functional properties of binders at intermediate temperatures.

ASAs improved the MR too. Among all ASA-contained specimens, PC2B had the highest resilient modulus. In specimens containing ASA (A) and (C), the increase was up to $50 \%$ PET, but higher percentages reduced the MR. While the MR of the PC2B was $15 \%$ higher than that of the virgin mixture, MR of the PC3C was about $1 \%$ higher, which indicates that composites rich in PET stiffen the binder/ polymer interface, while those rich in CR act as dispersed elements, instead of bitumen, causing the binder's storage modulus to improve due to their stiffer structure rather than that of the virgin binder. According to Figure 8, the ASAcontained specimens had higher MR than the virgin mixture in wet conditions; those containing 50\% PET and 50\% CR with ASA (B) had the highest MR value. As Figure 9 shows that all modified mixtures satisfy the Standard's minimum requirement (70\%), hence we may conclude that the ASAs improve the mixture resistance against the water damage. Among all the specimens, the virgin mixture had a lower RMR than the minimum (required in the Standard). Earlier studies have shown that ASAs improve the specimens' MR and the water susceptibility resistance [24-29].

4.2.2. ITS Test. To evaluate the effects of different additives on the specimens' tensile behavior, the ITS test was applied where higher ITS mixes showed more resistance against the moisture damage. According to Figure 10 that shows the ITS results for the original and modified specimens, the PET-/ CR-modified specimens had greater ITS values than the original one. An increase of up to 50\% in PET increased the ITS, but, beyond that (up to $75 \%$ ), the increasing trend was reversed and the ITS began to decrease. An increase in CR 


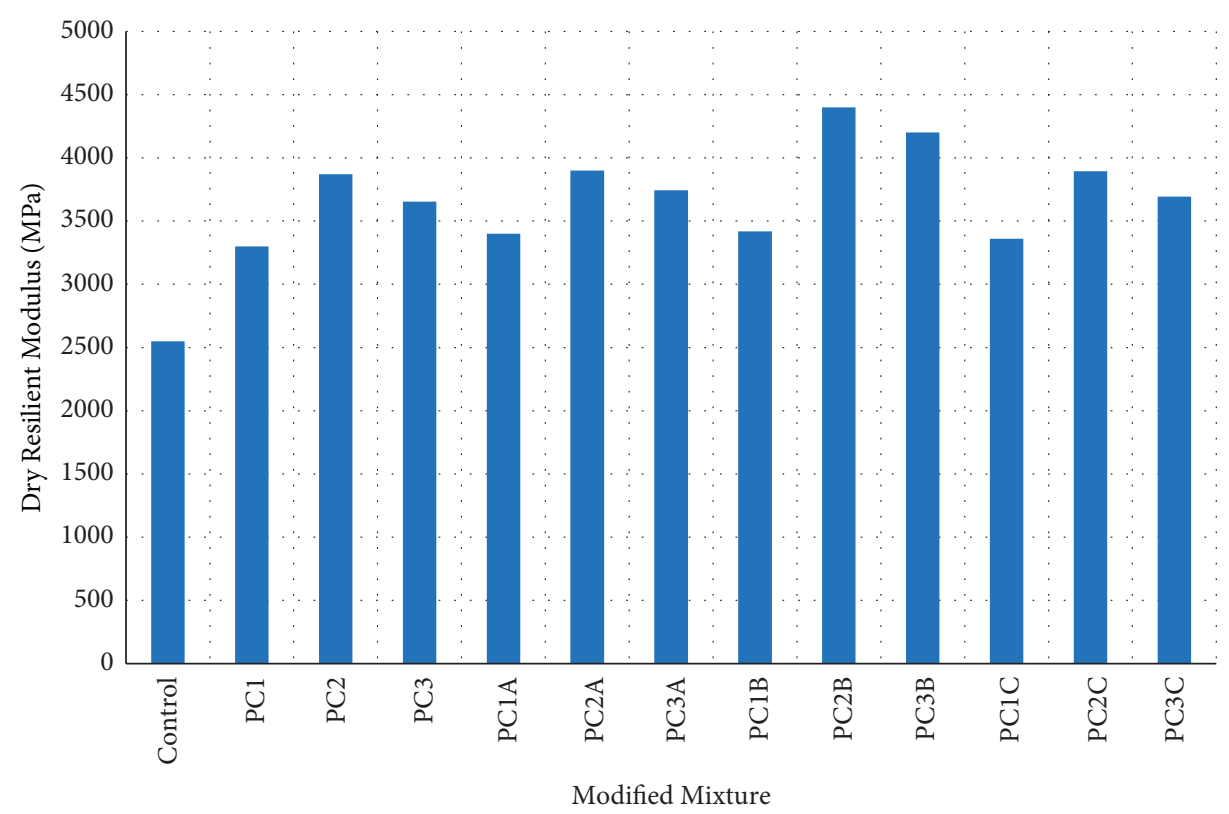

FIGURE 7: Results of resilient modulus of modified mixtures in dry conditions.

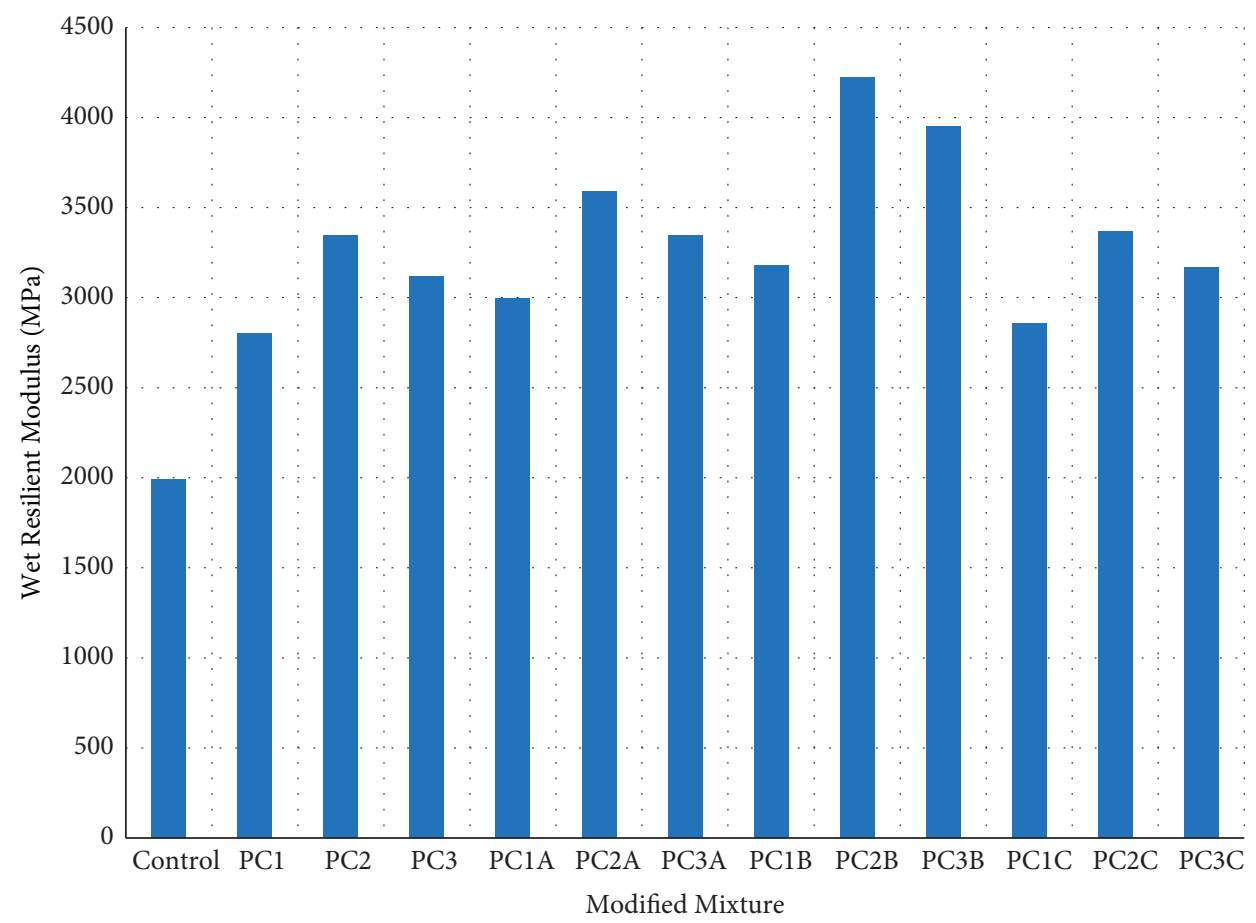

FIGURE 8: Results for the resilient modulus of modified mixtures in wet conditions.

caused the additive distribution in the bitumen matrix to decline which could probably be attributed to the CR partial cross-linking and limited thermoplastic PET swelling [35].

Results showed that ASAs improved the ITS of the PET-/ CR-contained specimens; the ITS of PC2B was the highest and ASA (B) improved the ITS the most.

The more the bitumen-to-aggregate cohesion was, the greater was the ITS [55], whereas adding PET/CR increased the cohesion/adhesion and adding ASA reduced it.
According to Figure 11 that shows the ITS results in wet conditions, the PET/CR addition improved the ITS of the virgin binder and addition of ASAs increased it in moist conditions. Among all ASA-contained specimens, PC2B had the highest ITS and TSR. In Figure 12, the virgin binder TSR was lower than $70 \%$ and PC1 and PC3 mixes had the least value required by the Standard. Earlier studies [24-29] have also confirmed that ASAs improve the mixture's moisture susceptibility resistance and ITS. 


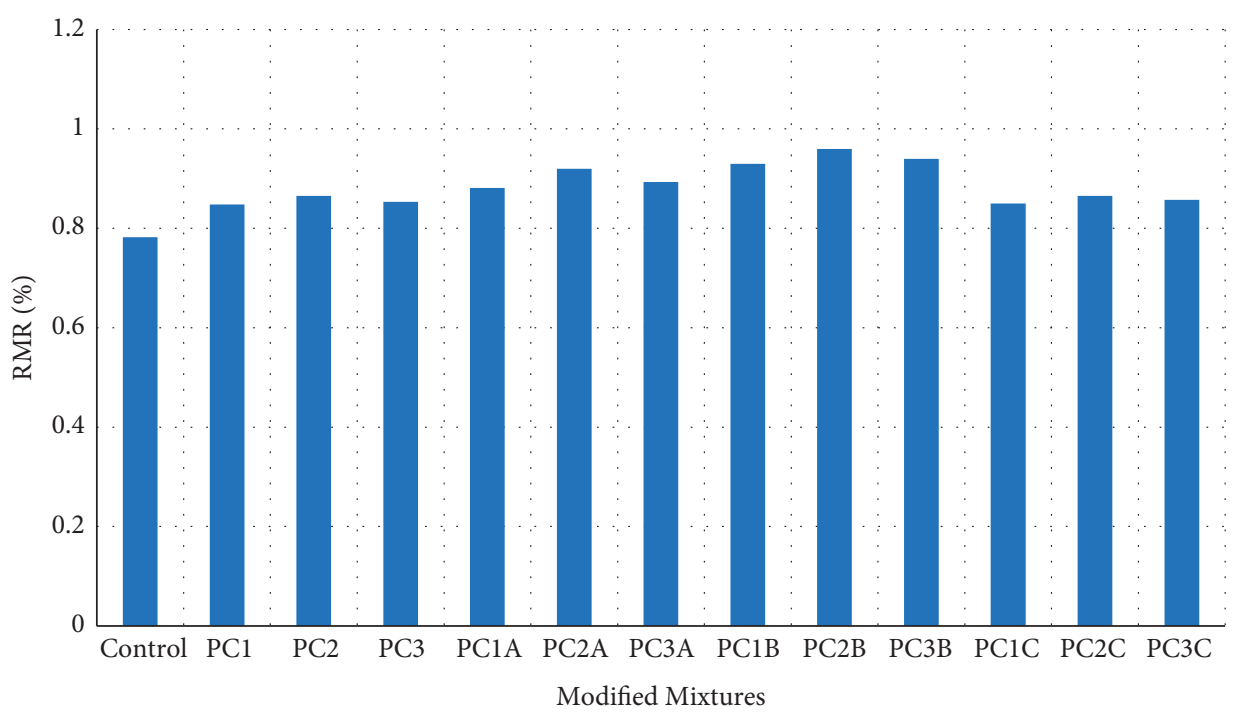

FIgURE 9: Results of RMR.

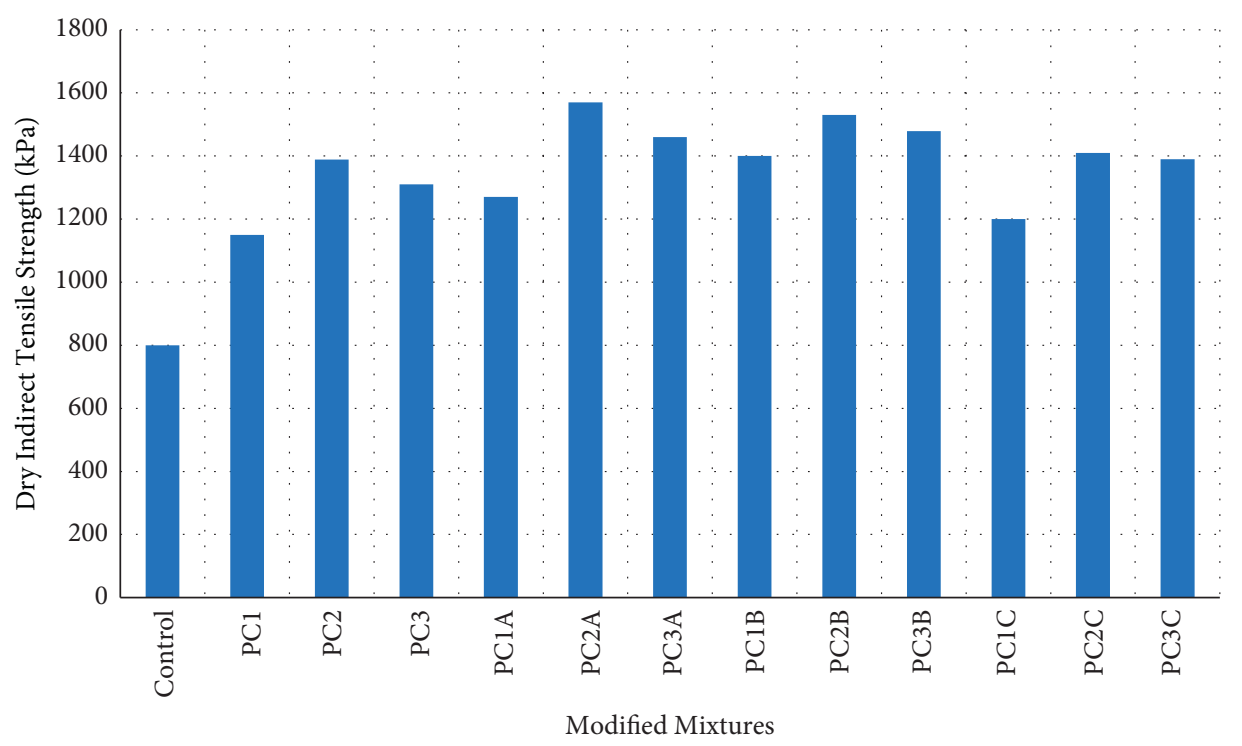

Figure 10: ITS values of mixtures in dry conditions.

4.2.3. Results of FE. In Figure 13, where the fracture energy density for different specimens are displayed, PET/CR increased the specimens' fracture energy and elasticity leading to an increase in its strain energy and resistance to cracking. At $50 \% \mathrm{PET}$, the fracture energy reached a maximum and then decreased by adding more PET. Addition of $50 \%$ PET and $50 \%$ CR improved the specimen's fatigue resistance, but higher PET values reduced it. Addition of ASAs improved the specimen's FE, and ASA (B) performed the best. According to Figure 14 which illustrates the fracture energy in wet conditions, specimens containing ASA (B) had the highest FE values with a similar trend under both wet and dry conditions. In Figure 15, all mixes, except the virgin binder, met the minimum values required by the Standard and PC2B had the highest FER.
4.2.4. Results of the Texas Boiling Test. In studying the formation of water sensitivity, the Texas boiling test is considered an empirical test since it is based on the researcher's observations. Hence, each sample image is processed after the test to quantify the results. For a precise analysis, images were divided into black areas showing the binder-coated parts of aggregates and white areas referring to the uncoated parts. Based on their brightness, the areas were marked with digits varying from 0 (quite black pixels) to 255 (quite white pixels) (Figure 16) and coded on the MATLAB Software. Images on the left refer to the actual pictures and those on the right show the analyzed ones. Those on the top indicate the pretest samples and those on the bottom show the posttest ones. Percent reductions in coated aggregates are listed in Table 9. According to the results, $\mathrm{PC} 2 \mathrm{~B}$ has the highest resistance against moisture damage; the same is the trend for the TSR. 


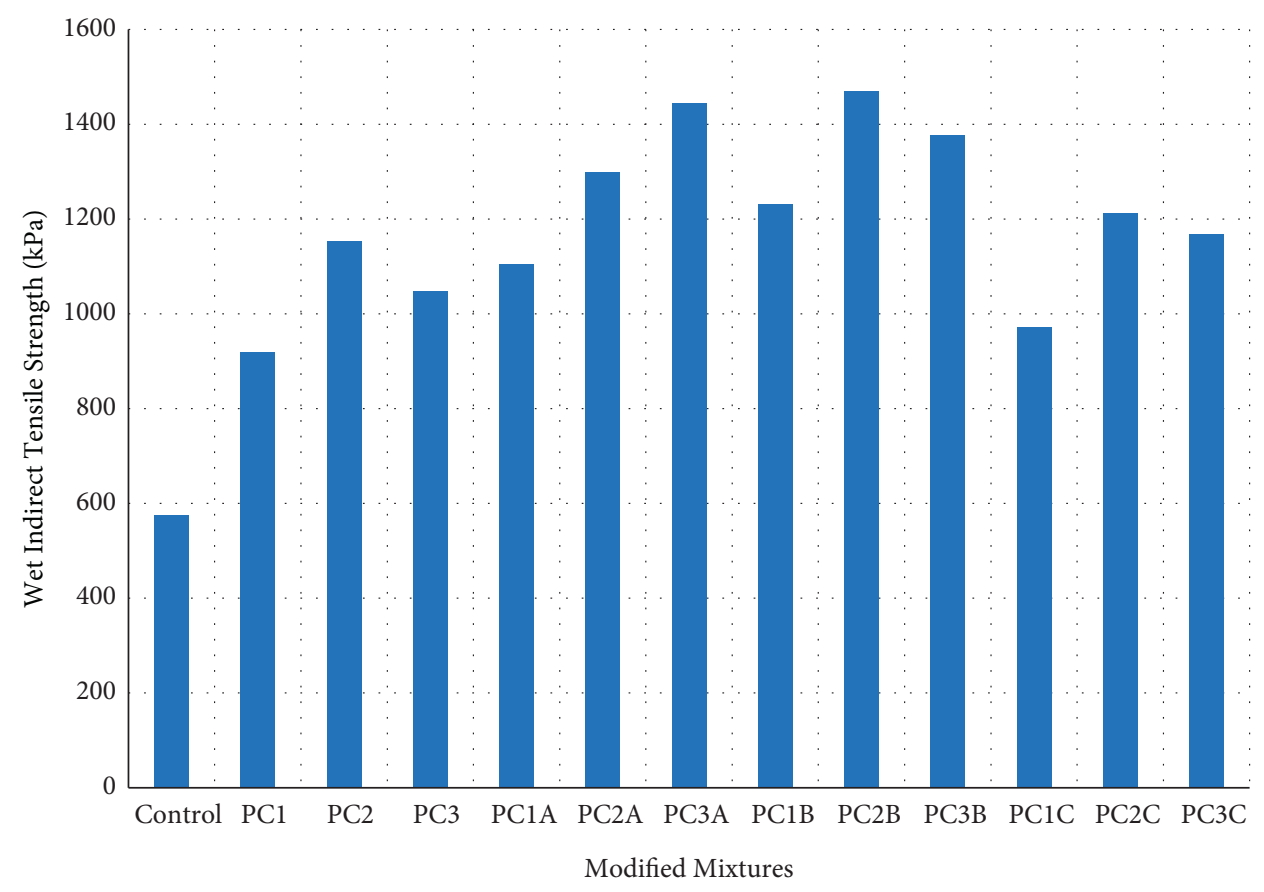

FIGURE 11: ITS values of mixtures in wet conditions.

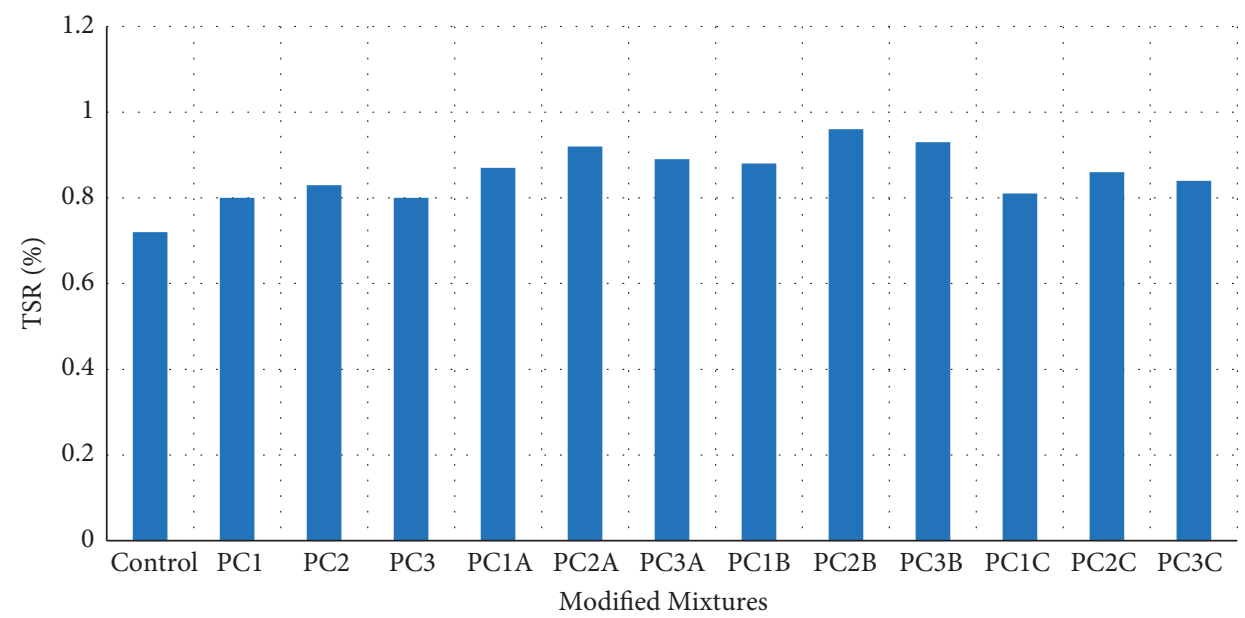

FIgURe 12: TSR values.

4.2.5. AASHTO T283 Test Results. If the ITS test continues until the specimen cracks and splits, its inner surface can be examined for the moisture damage performance. This was done under both conditioned and unconditioned modes (Figures 17(a) and 17(c)).

As the binder and ASAs were mixed, ASAs amines and binder anhydrides interacted and produced organogels, which improved the mixture performance more than amines or anhydrides.
Mixtures with ASA (B) have a better aggregate coating, and as aggregates get coarser, the failure surface becomes rougher.

4.2.6. Data Analysis Method. To analyze the data, this study made use of the two-factor (warm additive and ASA) analysis of variance (ANOVA) (Tables 10-12) considering MR, ITS, FE, RMR, TSR, and FER as dependent variables 


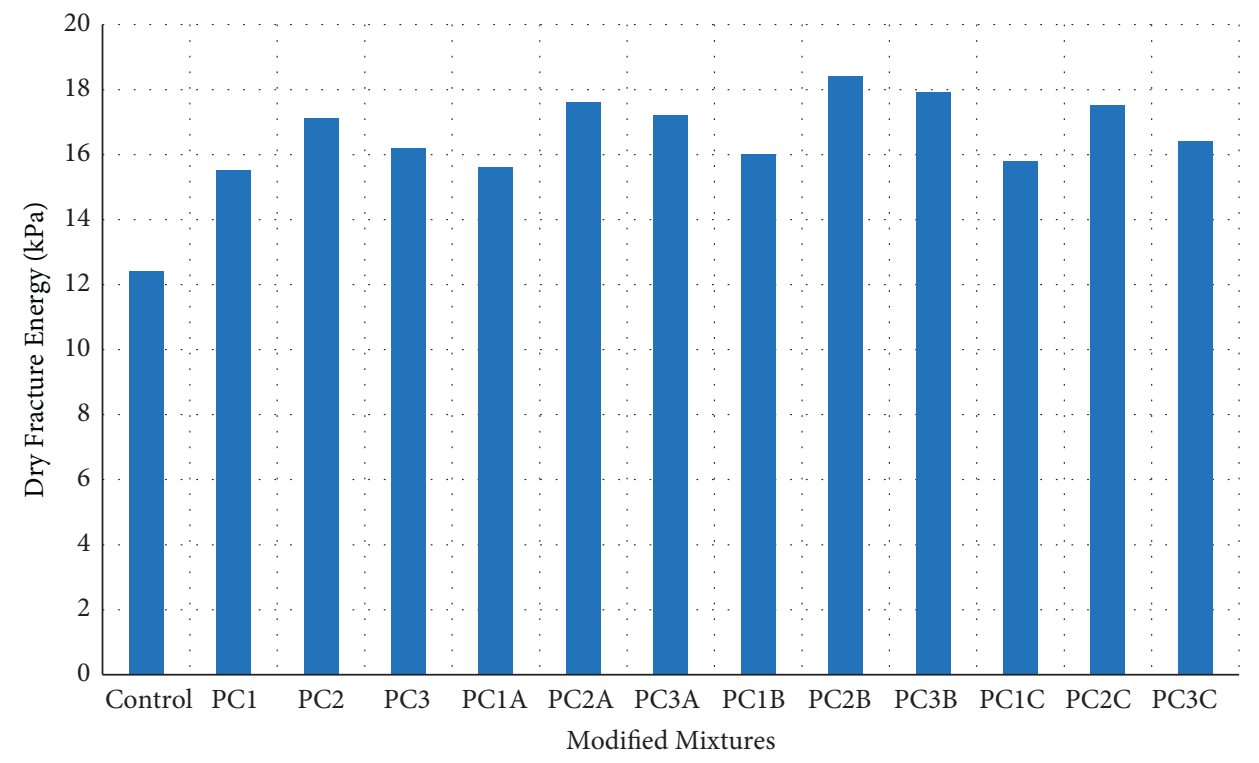

Figure 13: Fracture energy of different mixtures in dry conditions.

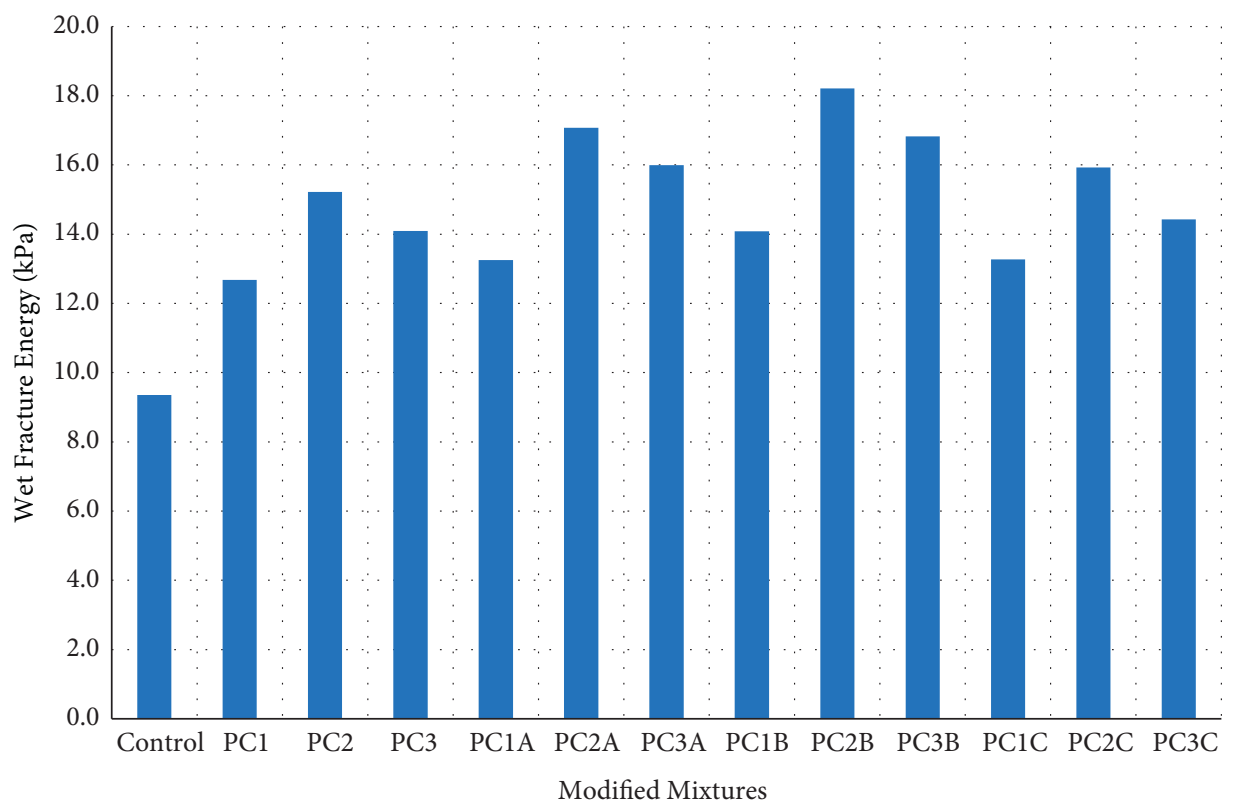

Figure 14: Fracture energy of different mixtures in wet conditions. 


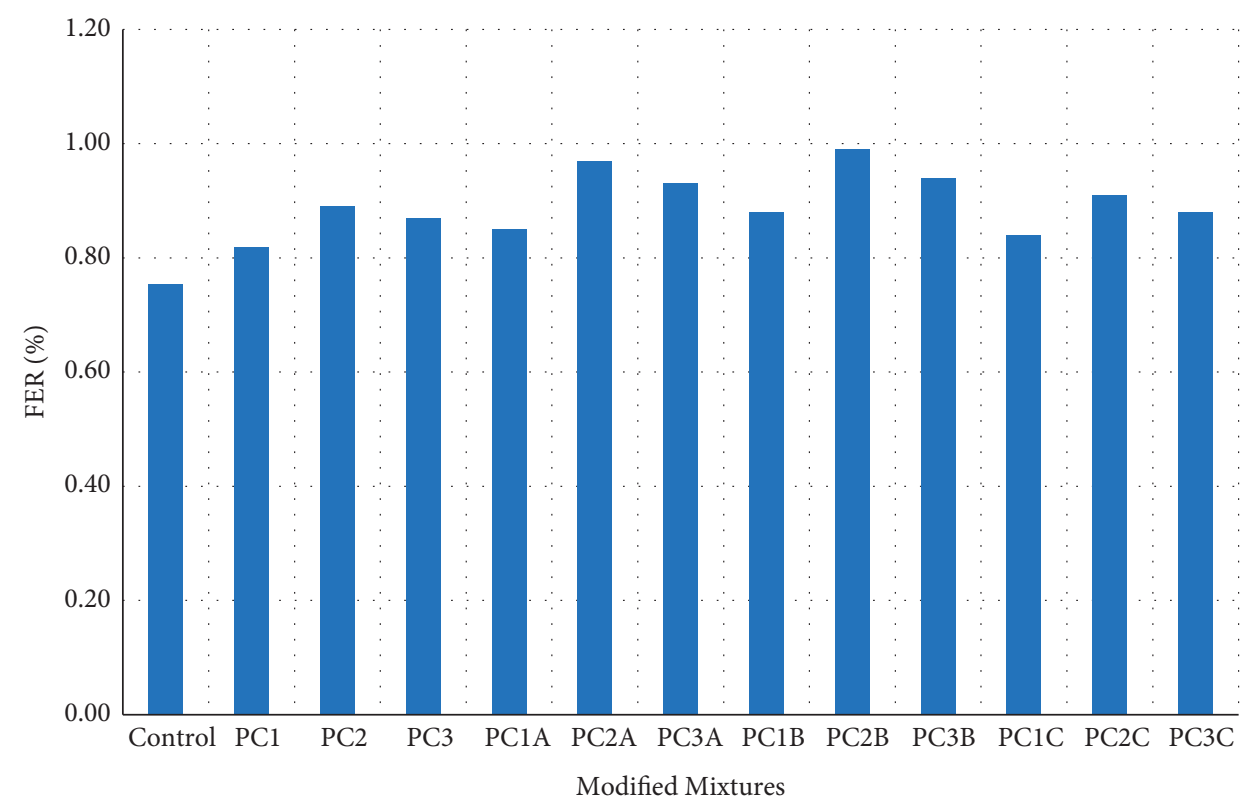

FIGURE 15: FER results.
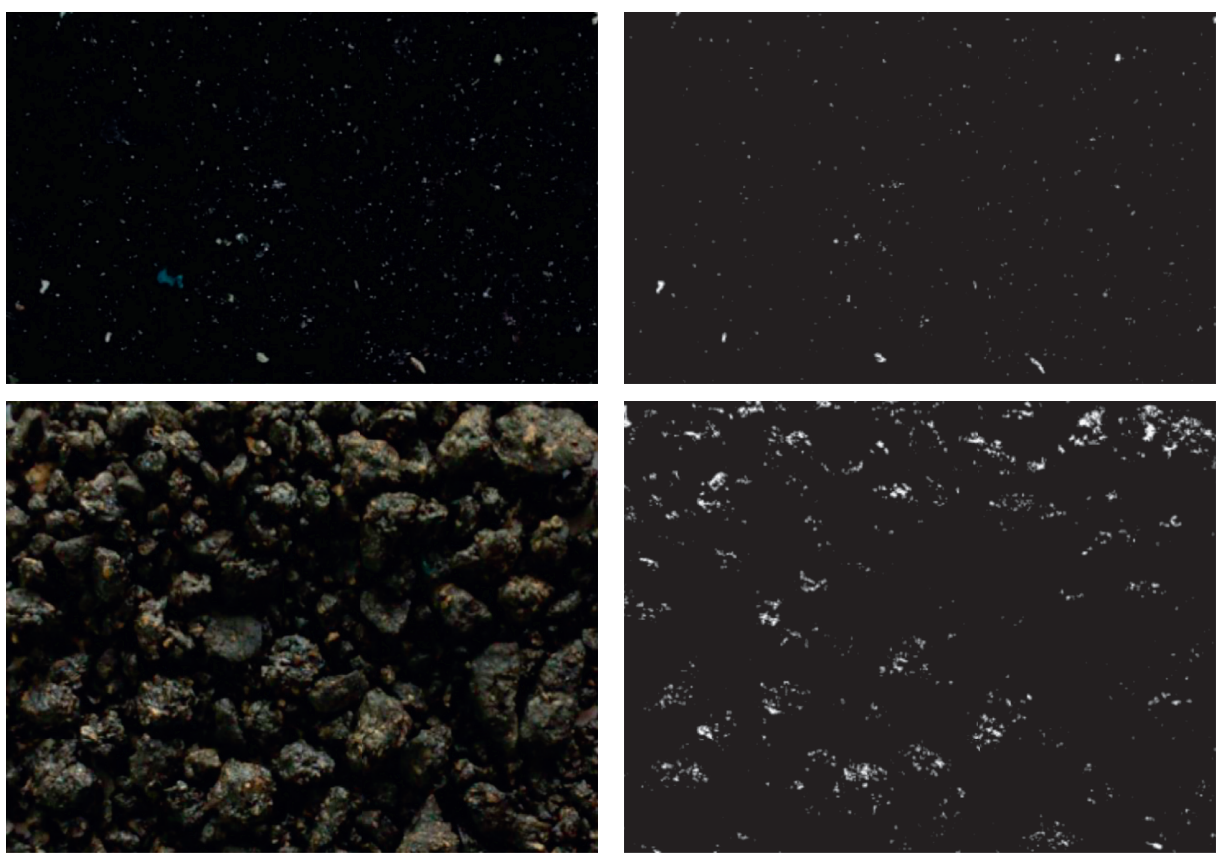

FIGURE 16: Steps for image processing on a special specimen. 
TABLE 9: Mixture's image processing results.

\begin{tabular}{lr}
\hline Mixture type & Result (\%) \\
\hline Control & $24-34$ \\
PC1 & $19-27$ \\
PC2 & $15-27$ \\
PC3 & $14-34$ \\
PC1A & $16-26$ \\
PC2A & $11-34$ \\
PC3A & $10-19$ \\
PC1B & $15-24$ \\
PC2B & $10-20$ \\
PC3B & $8-15$ \\
PC1C & $18-25$ \\
PC2C & $14-23$ \\
PC3C & $12-30$ \\
\hline
\end{tabular}

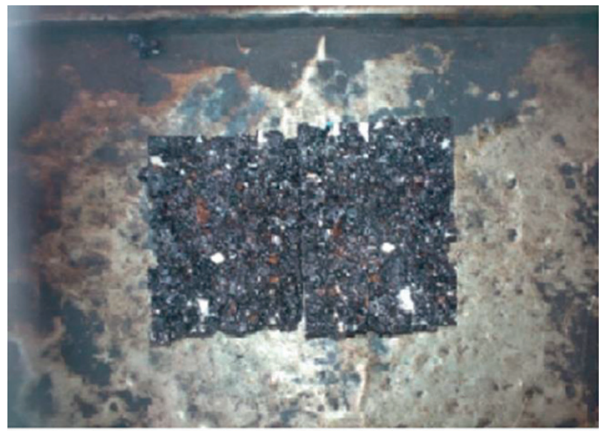

(a)

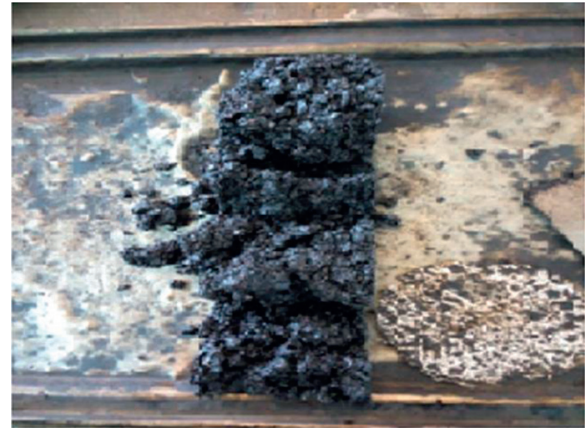

(b)

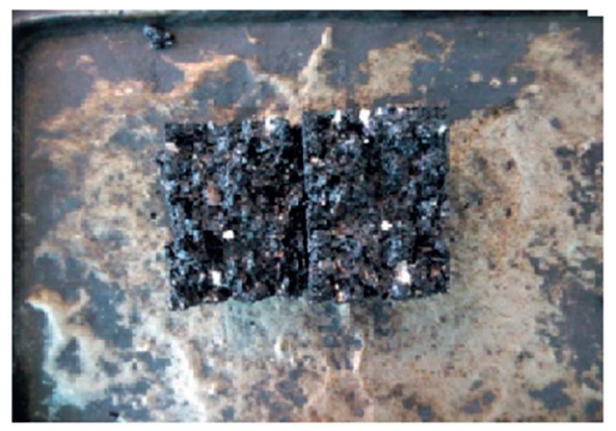

(c)

FIGURE 17: Failure surface for modified mixtures.

TAble 10: Two-way ANOVA: ITS versus CR, PET, and ASA.

\begin{tabular}{|c|c|c|c|c|c|}
\hline Source & DF & Adj. SS & Adj. MS & $F$-value & $p$ value \\
\hline \multicolumn{6}{|l|}{ ITS $_{\text {dry }}$} \\
\hline PET & 3 & 63179902 & 21059967 & 5484.68 & $p \leq 0.001$ \\
\hline CR & 3 & 7234759 & 2813495 & 1390 & $p \leq 0.001$ \\
\hline ASAs & 3 & 3562852 & 1781426 & 463.94 & $p \leq 0.001$ \\
\hline Interaction & 27 & 203194 & 33866 & 8.82 & $p \leq 0.001$ \\
\hline Error & 24 & 92155 & 3840 & & \\
\hline Total & 51 & 67038102 & & & \\
\hline \multicolumn{6}{|l|}{ ITS $_{\text {wet }}$} \\
\hline PET & 3 & 54168721 & 20112135 & 4687 & $p \leq 0.001$ \\
\hline $\mathrm{CR}$ & 3 & 8392013 & 3290389 & 2901 & $p \leq 0.001$ \\
\hline ASAs & 3 & 3461146 & 1526358 & 368.29 & $p \leq 0.001$ \\
\hline
\end{tabular}


TABle 10: Continued.

\begin{tabular}{|c|c|c|c|c|c|}
\hline Source & DF & Adj. SS & Adj. MS & $F$-value & $p$ value \\
\hline Interaction & 27 & 203194 & 33866 & 6.53 & $p \leq 0.001$ \\
\hline Error & 24 & 88432 & 3576 & & \\
\hline Total & 51 & 58457239 & & & \\
\hline \multicolumn{6}{|l|}{ TSR } \\
\hline PET & 3 & 435.5 & 386.6 & 235.4 & $p \leq 0.001$ \\
\hline CR & 3 & 391.2 & 367.3 & 251.4 & $p \leq 0.001$ \\
\hline ASAs & 3 & 358.3 & 355.9 & 278.5 & $p \leq 0.001$ \\
\hline Interaction & 27 & 405.8 & 380.4 & 302.1 & $p \leq 0.001$ \\
\hline Error & 24 & 6.67 & 10.7 & & \\
\hline Total & 51 & 1764.34 & & & \\
\hline
\end{tabular}

DF: degrees of freedom; MS: mean square; SS: sum of the squares.

TABle 11: Two-way ANOVA: $M_{r}$ versus PET, CR, and ASAs.

\begin{tabular}{|c|c|c|c|c|c|}
\hline Source & $\mathrm{DF}$ & Adj. SS & Adj. MS & $F$-value & $p$ value \\
\hline \multicolumn{6}{|l|}{$M_{r \mathrm{dry}}$} \\
\hline PET & 3 & 95769233 & 31923078 & 4014.23 & $p \leq 0.001$ \\
\hline CR & 3 & 6348901 & 2739461 & 1304 & $p \leq 0.001$ \\
\hline ASA & 3 & 4214721 & 2107361 & 264.99 & $p \leq 0.001$ \\
\hline Interaction & 27 & 1786681 & 297780 & 37.44 & $p \leq 0.001$ \\
\hline Error & 24 & 190859 & 7952 & & \\
\hline Total & 51 & 101961494 & & & \\
\hline \multicolumn{6}{|l|}{$M_{r \text { wet }}$} \\
\hline PET & 3 & 92478365 & 29713463 & 3686 & $p \leq 0.001$ \\
\hline CR & 3 & 4201305 & 4678123 & 2021 & $p \leq 0.001$ \\
\hline ASA & 3 & 3912547 & 2011254 & 231 & $p \leq 0.001$ \\
\hline Interaction & 27 & 1683484 & 286674 & 31.68 & $p \leq 0.001$ \\
\hline Error & 24 & 186427 & 7212 & & \\
\hline Total & 51 & 91745421 & & & \\
\hline \multicolumn{6}{|l|}{ RMR } \\
\hline PET & 3 & 422.8 & 321.3 & 219.3 & $p \leq 0.001$ \\
\hline CR & 3 & 382.6 & 103.6 & 248.6 & $p \leq 0.001$ \\
\hline ASA & 3 & 346.6 & 3.42 .5 & 261.3 & $p \leq 0.001$ \\
\hline Interaction & 27 & 398.3 & 325.6 & 289.4 & $p \leq 0.001$ \\
\hline Error & 24 & 6.21 & 9.4 & & \\
\hline Total & 51 & 1735.7 & & & \\
\hline
\end{tabular}

DF: degrees of freedom; MS: mean square; SS: sum of the squares.

TABle 12: Two-way ANOVA: fracture energy versus PET, CR, and ASAs.

\begin{tabular}{|c|c|c|c|c|c|}
\hline Source & DF & Adj. SS & Adj. MS & $F$-value & $p$ value \\
\hline \multicolumn{6}{|l|}{$\mathrm{FE}_{\mathrm{dry}}$} \\
\hline PET & 3 & 123.4 & 52.6 & 5.23 & $p \leq 0.001$ \\
\hline CR & 3 & 111.4 & 48.4 & 3.42 & $p \leq 0.001$ \\
\hline ASAs & 3 & 98.4 & 44.7 & 2.64 & $p \leq 0.001$ \\
\hline Interaction & 27 & 100.4 & 10.4 & 1.12 & $p \leq 0.001$ \\
\hline Error & 24 & 24 & 8.2 & & \\
\hline Total & 51 & 345.2 & & & \\
\hline \multicolumn{6}{|l|}{$\mathrm{FE}_{\text {wet }}$} \\
\hline PET & 3 & 98.3 & 42.7 & 4.2 & $p \leq 0.001$ \\
\hline CR & 3 & 85.2 & 39.2 & 3.3 & $p \leq 0.001$ \\
\hline ASAs & 3 & 73.4 & 34.6 & 2.1 & $p \leq 0.001$ \\
\hline Interaction & 27 & 86.4 & 27.5 & 0.98 & $p \leq 0.001$ \\
\hline Error & 24 & 19 & 6.7 & & \\
\hline Total & 51 & 282.1 & & & \\
\hline
\end{tabular}


TABle 12: Continued.

\begin{tabular}{lccccc}
\hline Source & DF & Adj. SS & Adj. MS & $F$-value & $p$ value \\
\hline FER & & & & 22.6 & 1.2 \\
PET & 3 & 68 & 20.6 & 1.15 & 1.1 \\
CR & 3 & 56.8 & 18.2 & 0.88 & $p \leq 0.001$ \\
ASAs & 3 & 51 & 13.2 & & \\
Interaction & 27 & 15 & 4.2 & \\
Error & 24 & 195 & & \\
Total & 51 & & & \\
\hline
\end{tabular}

DF: degrees of freedom; MS: mean square; SS: sum of the squares.

that were highly affected by different warm-additive combinations and warm additive-ASA interactions. Results showed that the warm additive had meaningful effects on MR, ITS, and FE; the same was true for the effects of the warm additive-ASA interaction.

\section{Conclusion}

The present study was aimed to examine the water resistance benefits by adding PET/CR and three different ASAs to SMA mixtures. To this end, several moisture damage tests (RMR, FER, AASHTO T283, and boiling water) were performed, the results of which can be summarized as follows:

(i) Addition of PET and CR leads to decreasing the penetration grade and increasing the softening point and viscosity due to the stiffening of binder. By increasing the PET/CR percentage, the binder becomes stiffer. Binders modified by antistripping, ASA (B), have the highest influence to stiffen binder followed by ASAs (A) and (C).

(ii) Addition of PET and CR improves the rutting resistance of binder, and by increasing the PET/CR percentage, the rutting resistance increases. Regardless of their types, ASAs increase the rutting parameter. As PET is a thermoplastic material and stiffens the bitumen more than the rubber part, more PET can increase the rutting resistance. Mixes modified by ASA (B) are more rut-resistant, probably because organogels are formed when ASAs are added to the PET-/CR-modified bitumen.

(iii) Adding PET and CR modifiers resulted in higher ITS values than the control mixture. Applying ASAs to PET-/CR-modified specimens increased the ITS values; PC2B had the highest ITS value. This might be due to the formation of a continuous elastic network and rubber powder as an elastic component compensates the undesirable (stiffening) effects of PET as the plastic constituent resulting in improved functional properties of binders at intermediate temperatures.

(iv) Regarding the resilient modulus, PET/CR modification increased it by $30 \%$ compared to the unmodified mixture, because the mixture flexibility increased when it was modified by PET and CR. Previous studies confirmed that the addition of PET/CR improved this modulus and stated that an increase in $\mathrm{CR}$ in the $\mathrm{PET} / \mathrm{CR}$ ratio declined the additive distribution in the bitumen matrix due, maybe, to the CR partial cross-linking and low thermoplastic PET swelling. This might be due to the formation of a continuous elastic network and rubber powder as an elastic component compensates the undesirable (stiffening) effects of PET as the plastic constituent resulting in improved functional properties of binders at intermediate temperatures. Similarly, ASAs increased the MR; PC2B had the highest value among all ASA-contained samples.

(v) Test results showed that PET/CR modification increased the FE due, which can be attributed to the sample's enhanced elasticity and, hence, improved mixture resistance against fatigue cracking. This might be due to the formation of a continuous elastic network and rubber powder as an elastic component compensates the undesirable (stiffening) effects of PET as the plastic constituent resulting in improved functional properties of binders at intermediate temperatures. Likewise, ASA increased the FE and ASA (B) had the greatest effect; PC2B had the highest FE value.

(vi) Results of the Texas boiling test showed that PC2B performed the best against water distress; the same was the trend for the TSR.

\section{Data Availability}

The data used to support the findings of this study are available from the corresponding author upon request.

\section{Conflicts of Interest}

The authors declare that they have no conflicts of interest.

\section{References}

[1] B. Rezvan and Z. Hassan, "Evaluation of rutting performance of stone matrix asphalt mixtures containing warm mix additives," Journal of Central South University, vol. 24, no. 2, pp. 360-373, 2017.

[2] R. Babagoli, M. Hasaninia, and N. Mohammad Namazi, "Laboratory evaluation of the effect of Gilsonite on the performance of stone matrix asphalt mixtures," Road Materials and Pavement Design, vol. 16, no. 4, pp. 889-906, 2015. 
[3] A. Vargas-Nordcbeck and F. Jalali, "Life-extending benefit of crack sealing for pavement preservation," Transportation Research Record, vol. 2674, 2020.

[4] G. H. Hamedi, S. Ali, and M. R. Esmaeeli, "Investigate the effect of using polymeric anti-stripping additives on moisture damage of hot mix asphalt," European Journal of Environmental and Civil Engineering, vol. 25, pp. 1-14, 2018.

[5] R. S. Ashtiani, M. Ali, C. Licon, C. Tirado, J. Gonzales, and S. Rocha, "Characterization and quantification of traffic load spectra in Texas overweight corridors and energy sector zones," Tx-06965: Characterization and Quantification of Traffic Load Spectra in Texas Overweight Corridors and Energy Sector Zones, University of Texas at El Paso, El Paso, TX, US, 2019.

[6] Y. Li, D. J. White, and R. Lee Peyton, "Composite material from fly ash and post-consumer PET," Resources, Conservation and Recycling, vol. 24, no. 2, pp. 87-93, 1998.

[7] S. R. Shukla and A. M. Harad, "Aminolysis of polyethylene terephthalate waste," Polymer Degradation and Stability, vol. 91, no. 8, pp. 1850-1854, 2006.

[8] N. Torres, J. J. Robin, and B. Boutevin, "Study of thermal and mechanical properties of virgin and recycled poly(ethylene terephthalate) before and after injection molding," European Polymer Journal, vol. 36, no. 10, pp. 2075-2080, 2000.

[9] R. Navarro, S. Ferrandiz, J. Lopez, and V. J. Segui, "The influence of polyethylene in the mechanical recycling of polyethylene terephtalate," Journal of Materials Processing Technology, vol. 195, no. 1, pp. 110-116, 2008.

[10] T. BaghaeeMoghaddam, M. Soltani, and M. R. Karim, "Evaluation of permanent deformation characteristics of unmodified and Polyethylene Terephthalate modified asphalt mixtures using dynamic creep test," Materials \& Design, vol. 53, pp. 317-324, 2014.

[11] D. LoPresti and G. Airey, "Tyre rubber-modified bitumens development: the effect of varying processing conditions," Road Materials and Pavement Design, vol. 14, no. 4, pp. 888-900, 2013.

[12] H. Kim, K.-D. Jeong, M. S. Lee, and S.-J. Lee, "Performance properties of CRM binders with wax warm additives," Construction and Building Materials, vol. 66, pp. 356-360, 2014.

[13] H. H. Kim and S.-J. Lee, "Effect of crumb rubber on viscosity of rubberized asphalt binders containing wax additives," Construction and Building Materials, vol. 95, pp. 65-73, 2015.

[14] H. H. Kim, M. Mazumder, and S.-J. Lee, "Recycling of aged asphalt binders with wax warm additives," Road Materials and Pavement Design, vol. 19, no. 5, pp. 1203-1215, 2018.

[15] Y. Yan, R. Roque, D. Hernando, and S. Chun, "Cracking performance characterisation of asphalt mixtures containing reclaimed asphalt pavement with hybrid binder," Road Materials and Pavement Design, vol. 20, no. 2, pp. 347-366, 2019.

[16] A. Ameli, R. Babagoli, and M. Aghapour, "Laboratory evaluation of the effect of reclaimed asphalt pavement on rutting performance of rubberized asphalt mixtures," Petroleum Science and Technology, vol. 34, no. 5, pp. 449-453, 2016.

[17] S. Wang, Q. Wang, X. Wu, and Y. Zhang, "Asphalt modified by thermoplastic elastomer based on recycled rubber," Construction and Building Materials, vol. 93, pp. 678-684, 2015.

[18] Q. Lu and J. T. Harvey, "Field investigation of factors associated with moisture damage in asphalt pavements," in Proceedings of the 10th International conference on asphalt pavements (ISAP), pp. 691-700, Quebec, Canada, August 2006.
[19] F. Jalali, A. Vargas-Nordcbeck, and M. Nakhaei, "Full-scale probabilistic assessment of asphalt surface treatments: the case study of lee road 159," in Proceedings of the International Airfield and Highway Pavements, Chicago, IL, July 2019.

[20] Satvati, Sajjad, A. L Jeramy et al., "A novel performance-based economic analysis approach," in Proceedings of the 12th International Conference on Low-Volume Roads, p. 207, Kalispell, MT, US, September 2019.

[21] M. Arabani, S. A. Tahami, and G. H. Hamedi, "Performance evaluation of dry process crumb rubber-modified asphalt mixtures with nanomaterial," Road Materials and Pavement Design, vol. 19, no. 5, pp. 1241-1258, 2018.

[22] B. Cetin, S. Satvati, J. C. Ashlock, and Charles Jahren, Performance-Based Evaluation of Cost-Effective Aggregate Options for Granular Roadways, Iowa State University, Ames, IA, US, 2019.

[23] Y. D. Wang, A. Ghanbari, B. S. Underwood, and Y. R. Kim, "Development of a performance-volumetric relationship for asphalt mixtures," Transportation Research Record: Journal of the Transportation Research Board, vol. 2673, no. 6, pp. 416-430, 2019.

[24] F. Xiao and S. N. Amirkhanian, "Effects of liquid antistrip additives on rheology and moisture susceptibility of water bearing warm mixtures," Construction and Building Materials, vol. 24, no. 9, pp. 1649-1655, 2010.

[25] M. Nazirizad, A. Kavussi, and A. Abdi, "Evaluation of the effects of anti-stripping agents on the performance of asphalt mixtures," Construction and Building Materials, vol. 84, pp. 348-353, 2015.

[26] D.-W. Park, W.-J. Seo, J. Kim, and H. V. Vo, "Evaluation of moisture susceptibility of asphalt mixture using liquid antistripping agents," Construction and Building Materials, vol. 144, pp. 399-405, 2017.

[27] C.F. Zheng, Y. Qin, D. Lv, T. Zhang, X.Y. Liu, and S. Zheng, "Effects of anti-stripping agents on the microscopic strength of mineral aggregate contact surface," Construction and Building Materials, vol. 49, pp. 627-634, 2013.

[28] F. Xiao, W. Zhao, T. Gandhi, and S. N. Amirkhanian, "Influence of antistripping additives on moisture susceptibility of warm mix asphalt mixtures," Journal of Materials in Civil Engineering, vol. 22, no. 10, pp. 1047-1055, 2010.

[29] S. Selvaratnam, M. Zaman, and G. Laguros, "Laboratory evaluation of unmodified and polymer-modified performance-grade binders with anti-stripping additives," J. Eng. Comput. Archit. Sci. J. Int. (SJI), vol. 1, no. 2, 2007.

[30] D. Nasr and A. H. Pakshir, "Rheology and storage stability of modified binders with waste polymers composites," Road Materials and Pavement Design, vol. 20, no. 4, pp. 773-792, 2019.

[31] M. D. Earnest, "Performance characteristics of polyethylene terephthalate (PET) modified asphalt," 2015, https:// digitalcommons.georgiasouthern.edu/etd/1260.

[32] Z. Leng, R. K. Padhan, and A. Sreeram, "Production of a sustainable paving material through chemical recycling of waste PET into crumb rubber modified asphalt," Journal of Cleaner Production, vol. 180, pp. 682-688, 2018.

[33] M. H. Karahrodi, O. M. Jazani, S. M. R. Paran, K. Formela, and M. R. Saeb, "Modification of thermal and rheological characteristics of bitumen by waste PET/GTR blends," Construction and Building Materials, vol. 134, pp. 157-166, 2017.

[34] C. S. Mohanta, S. Anand, V. Yadav, R. Kumar Padhan, N. S. Raman, and R. P. Badoni, "Synergic effect of waste PET and sebacic acid on the rheology of crumb rubber modified 
bitumen," International Journal of Pavement Engineering, vol. 22, pp. 1-12, 2019.

[35] C. Zhu, G. Xu, H. Zhang, F. Xiao, S. Amirkhanian, and C. Wu, "Influence of different anti-stripping agents on the rheological properties of asphalt binder at high temperature," Construction and Building Materials, vol. 164, pp. 317-325, 2018.

[36] E. Ahmadinia, M. Zargar, M. R. Karim, M. Abdelaziz, and E. Ahmadinia, "Performance evaluation of utilization of waste polyethylene terephthalate (PET) in stone mastic asphalt," Construction and Building Materials, vol. 36, pp. 984-989, 2012.

[37] T. BaghaeeMoghaddam, M. R. Karim, and T. Syammaun, "Dynamic properties of stone mastic asphalt mixtures containing waste plastic bottles," Construction and Building Materials, vol. 34, pp. 236-242, 2012.

[38] T. BaghaeeMoghaddam, M. Soltani, and M. R. Karim, "Experimental characterization of rutting performance of polyethylene terephthalate modified asphalt mixtures under static and dynamic loads," Construction and Building Materials, vol. 65, pp. 487-494, 2014.

[39] A. Hassani, H. Ganjidoust, and A. A. Maghanaki, "Use of plastic waste (poly-ethylene terephthalate) in asphalt concrete mixture as aggregate replacement," Waste Management \& Research: The Journal for a Sustainable Circular Economy, vol. 23, no. 4, pp. 322-327, 2005.

[40] W. Rahman and A. Wahab, "Green pavement using recycled polyethylene terephthalate (PET) as partial fine aggregate replacement in modified asphalt," Procedia Engineering, vol. 53, pp. 124-128, 2013.

[41] F. Zhang and C. Hu, "Physical and rheological properties of crumb rubber/styrene-butadiene-styrene compound modified asphalts," Polymer Composites, vol. 38, no. 9, pp. 1918-1927, 2015.

[42] E. R. Brown and L. A. Cooley, Designing Stone Matrix Asphalt Mixtures for Rut-Resistant Pavements, Transport Res Board, Washington, DC, US, 1999.

[43] K. Naderi, M. Nakhaei, F. Jalali, A. N. Aliasghar, and D. H. Timm, in Proceedings of the Low PG Determination of Neat Binders: A Comparison Between AASHTO Procedure and Time Temperature Superposition Approach, Washington, DC, US, January 2019.

[44] M. Jafari, A. Akbari Nasrekani, M. Nakhaei, and A. Babazadeh, "Evaluation of rutting resistance of asphalt binders and asphalt mixtures modified with polyphosphoric acid," Petroleum Science and Technology, vol. 35, no. 2, pp. 141-147, 2017.

[45] T. W. Kennedy and J. N. Anagnos, Wet-dry Indirect Tensile Test for Evaluating Moisture Susceptibility of Asphalt Mixtures, The University of Texas at Austin, Austin, TX, US, 1984.

[46] S. Shihui, Z. Weiguang, W. Shenghua, M. Balasingam and M. Louay, Long-Term Field Performance of Warm Mix Asphalt Technologies, National Academies of Sciences, Engineering, and Medicine, Long-Term Field Performance of Warm Mix Asphalt Technologies, The National Academies Press, Washington, DC, USA, 2017.

[47] H. Ziari, R. Babagoli, and S. E. T. Razi, "The evaluation of rheofalt as a warm mix asphalt additive on the properties of asphalt binder," Petroleum Science and Technology, vol. 33, no. 21-22, pp. 1781-1786, 2015.

[48] Z. Hassan, D. Hassan, B. Rezvan, and A. Ali, "Influence of bentonite additive on bitumen and asphalt mixture properties," World Academy of Science, Engineering and Technology, vol. 6, 2012.
[49] N. Norouzi, A. Ameli, and R. Babagoli, "Investigation of fatigue behaviour of warm modified binders and warm-stone matrix asphalt (WSMA) mixtures through binder and mixture tests," International Journal of Pavement Engineering, vol. 22, pp. 1-10, 2019.

[50] H. Ziari, R. Babagoli, and A. Akbari, "Investigation of fatigue and rutting performance of hot mix asphalt mixtures prepared by bentonite-modified bitumen," Road Materials and Pavement Design, vol. 16, no. 1, pp. 101-118, 2015.

[51] H. Ziari, R. Babagoli, M. Ameri, and A. Akbari, "Evaluation of fatigue behavior of hot mix asphalt mixtures prepared by bentonite modified bitumen," Construction and Building Materials, vol. 68, pp. 685-691, 2014.

[52] F. Jalali, A. Vargas-Nordcbeck, and M. Nakhaei, "Role of preventive treatments in low-volume road maintenance Program: full-scale case study," Transportation Research Record, vol. 2673, 2019.

[53] B. Sengoz, A. Topal, and G. Isikyakar, "Morphology and image analysis of polymer modified bitumens," Construction and Building Materials, vol. 23, no. 5, pp. 1986-1992, 2009.

[54] R. K. Padhan, C. Mohanta, S. Anand, and A. Gupta, "Rheological evaluation of bitumen modified using antistripping additives synthesised from waste polyethylene terephthalate (PET)," International Journal of Pavement Engineering, vol. 21, pp. 1-9, 2018.

[55] R.P. Lottman, Predicting Moisture-Induced Damage to Asphaltic Concrete, Transportation Research Board, National Research Council, Washington, DC, US, 1978. 